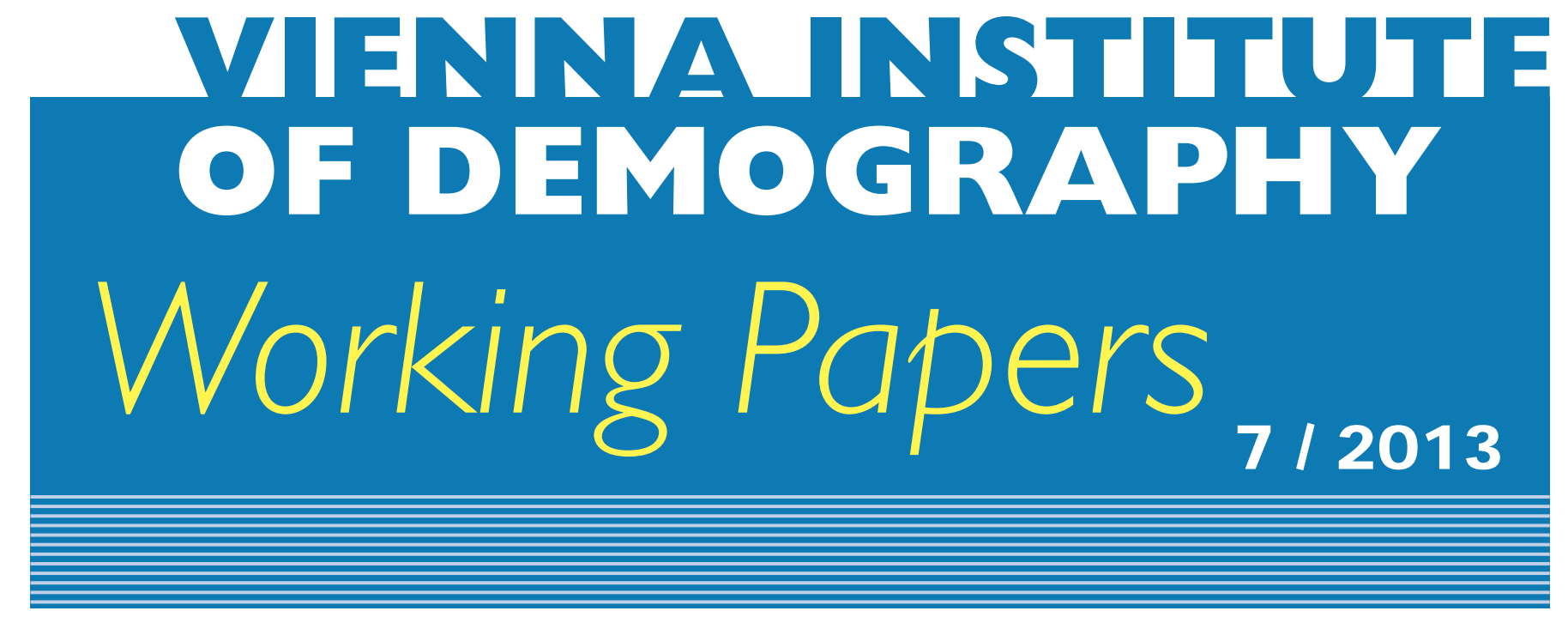

N ikola Sander, Guy J. Abel and Fernando Riosmena

Contributing Authors: Ayla Bonfiglio, Graeme Hugo, Lori Hunter, Siew-Ean Khoo, Douglas Massey, Philip Rees

\title{
The Future of International M igration: Developing Expert-Based Assumptions for Global Population Projections
}

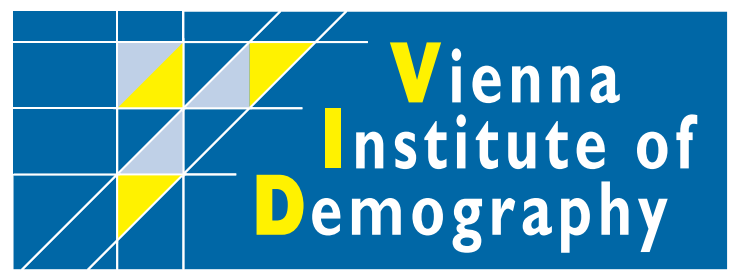

Vienna Institute of Demography Austrian Academy of Sciences

Wohllebengasse 12-14

A-I040Vienna $\cdot$ Austria

E-Mail:vid@oeaw.ac.at

Website: www.oeaw.ac.at/vid

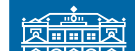

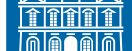

CA Austrian Academy of Sciences 


\begin{abstract}
This paper explores alternative future trajectories of international migration by applying a multiregional flow model to a new set of estimates of global bilateral migration flows developed by the second author. The innovations in population projections presented here are threefold: first, the projections are based on new flow estimates that are comparable at the world level rather than commonly used net migration measures; second, a set of alternative expert-based what-if scenarios is developed and a continuation of current trends until the year 2060 as the medium variant is assumed rather than assuming a convergence to zero net migration; third projections are carried out using directional migration probabilities in a multiregional cohort-component framework, where populations of all countries are projected simultaneously. A discussion of the baseline data, assumptions and model specifications is followed by a summary of key result on projected numbers of future migrants.
\end{abstract}

\title{
Keywords
}

International migration, population projections, multiregional demography, flow estimates.

\section{Authors}

Nikola Sander, Research Scholar, Wittgenstein Centre for Demography and Global Human Capital (IIASA, VID/ÖAW, WU), Vienna Institute of Demography/Austrian Academy of Sciences. Email: nikola.sander@oeaw.ac.at

Guy J. Abel, Research Scholar, Wittgenstein Centre for Demography and Global Human Capital (IIASA, VID/ÖAW, WU), Vienna Institute of Demography/Austrian Academy of Sciences. Email: guy.abel@oeaw.ac.at

Fernando Riosmena, Assistant Professor, Population Program, Institute of Behavioral Science, Department of Geography, University of Colorado at Boulder, USA. Email: fernando.riosmena@,colorado.edu

\section{Contributing Authors}

Ayla Bonfiglio, Graeme Hugo, Lori Hunter, Siew-Ean Khoo, Douglas Massey, and Philip Rees. The contributing authors have drafted parts of Sections 1 and 2.

\section{Acknowledgements}

We thank Ayla Bonfiglio, Philip Rees, James Raymer, Andrei Rogers, Graeme Hugo, Siew-Ean Khoo, Joel Cohen, David Coleman and Jeffrey Passel for participating in the meta expert meeting. We are grateful to William Butz, Philip Rees, Graeme Hugo and Ayla Bonfiglio for their comments on an earlier version of this paper. We thank Bilal Barakat for developing the online questionnaire interface. The research presented here is part of a large project by the Wittgenstein Centre on projecting global populations until 2100 . 


\section{Contents}

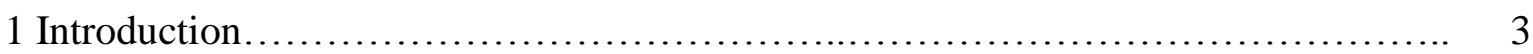

2 Migration Forces.............................................................. 5

2.1 The Geography and Timing of the Initiation of International Migration Flows ....................................................................... 5

2.2 The Continuation of Migration Flows................................. $\quad 7$

2.3 Economic Forces, Development, and Emigration......................... 8

2.4 Migration as an Adaptation Strategy to Climate and Environmental Change 9

2.5 Shocks to the System? Violence, Political Upheaval, and Displacement...... 11

2.6 The Effects of Migration Policies on Migration Dynamics................... 13

2.6.1 Immigration Policies........................................... 14

2.6.2 Asylum Policies ............................................. 15

2.6.3 Emigration Policies ........................................... 15

2.7 Socio-demographic Factors......................................... 16

2.7.1 The Demography of Labour Demand and Supply as Drivers of

Labour Migration.................................................. 16

2.7.2 Socio-demographic Drivers of Marriage Migration................ 17

2.7.3 Beyond Drivers: The Relevance of Understanding the

Demographic Profile of Migrants.................................... 18

3 Global Estimates of International Migration Flow Data........................... 18

4 Population Projections Using a Bi-regional Model................................. 23

5 Expert Views on the Future of Migration........................................ 24

5.1 Source Expert's Views from the Online Survey.......................... 25

5.2 Meta Expert's Views.................................................... 31

6 Specification and Justifications of Assumptions.................................. 34

6.1 The Medium Scenario.................................................. 35

6.2 Two Alternative 'what-if' Scenarios................................. 36

7 Projected Numbers of Migrants.................................................. 39

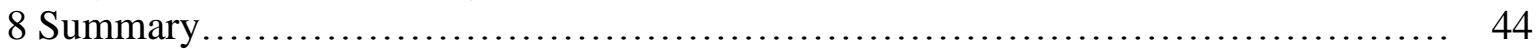

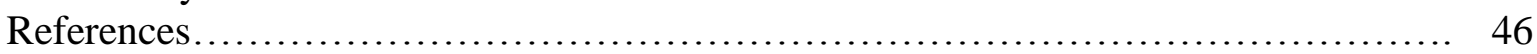

Appendix: Full List of Arguments................................................. 54 


\title{
The Future of International Migration: Developing Expert-Based Assumptions for Global Population Projections
}

\author{
Nikola Sander, Guy J. Abel and Fernando Riosmena \\ Contributing Authors: Ayla Bonfiglio, Graeme Hugo, Lori Hunter, Siew-Ean Khoo, Douglas \\ Massey, and Philip Rees.
}

Preliminary Version (October 20, 2013)

\section{Introduction}

Migration is a key means by which human beings act to preserve or enhance their well-being. Since Homo sapiens first emerged in Africa about 200,000 years ago, geographic mobility has been a prominent strategy for human adaptation and improvement (Cavalli-Sforza et al., 1994). In modern societies, people most commonly migrate to further their economic position or to join family members who migrated before them (Massey et al., 1993). Yet, many others move, both temporarily and permanently, with the more explicit purpose of reducing social, economic, political, or environmental vulnerability (Bardsley and Hugo, 2010; Hunter, 2005; Lundquist and Massey, 2005). All of these forms of human mobility frequently span international borders, oftentimes despite substantial barriers to international movement. ${ }^{1}$

Estimates of migration flows are the expression of these heterogeneous motivations. As the drivers of migration also vary conspicuously across nations (Clark et al., 2004; Massey and Sana, 2003) and evolve over time within countries (Lindstrom and Ramírez, 2010; Massey, 1990; Massey et al., 1994), they are particularly difficult to forecast. Even developing a homogeneous series of baseline estimates at a global level is very complex (Abel, 2013), further complicating forecasting efforts. Reliable baseline estimates are hard to obtain, for instance, given differences in the definitions across countries of what is an international migrant (Kupiszewska and Nowok, 2008) and due to the presence of sizable irregular or unauthorized flows in some nations (e.g., Passel et al. (2009).

Notwithstanding these difficulties, international migration has increasingly become, and

\footnotetext{
${ }^{1}$ Although international mobility may be particularly costly, (and thus, less common than intra-national movement), in no small part due to restrictive immigration policies and practices, transnational movement may still be likely and possible for individuals with access to various forms of human, financial, and social capital that can support and facilitate lawful and extra-legal moves.
} 
will remain, a crucial component of the population dynamics of many sending and receiving nations. While only 2 percent of the world's population lives outside of their country of birth, ${ }^{2}$ this figure is above 10 percent for nationals of countries like Mexico and El Salvador. Foreignborn shares are also substantial relative to the population of many migrant-receiving countries, with levels above 10 percent (in some cases well above) in North America, most of Western Europe and Oceania, and parts of South East Asia. At the extreme, this share has reached levels about 60-80 percent in some age groups in the oil-producing nations of the Gulf Cooperation Council. ${ }^{3}$ Furthermore, the origins and destinations of international migrants have become more diverse in the last four decades (Özden et al., 2011).

These shares imply the increasing importance of international migration as a component of national population growth (Zlotnik, 2004), reproduction (Ediev et al., 2007; Preston and Wang, 2007), and (to a lesser extent) the age structure of immigrant-receiving nations (Espenshade, 2001; Wu and Li, 2003). ${ }^{4}$ Because of their relevance, developing plausible quantitative central and alternative what-if scenarios has become increasingly important. The inclusion of realistic assumptions is hindered by the difficulties in measuring past migration flows required to quantify future levels of movements for projection models. Consequently, the accurate and realistic projection of longer-term migration (through both immigration and emigration rates) is one of the most difficult, but unavoidable, challenges in population forecasting.

This paper outlines our approach for meeting this challenge. We first present an overview of the economic, climate, political, policy and socio-demographic forces that affect migration. In Section 3, we discuss the available data to study international migration, before briefly summarising our methodology to estimate a set of bilateral migration flow tables of past movements between all countries that seeks to address the lack of comparable migration statistics at the global level. A more detailed discussion of the estimation methodology and the contemporary patterns and trends of global migration flows can be found in Abel (2013a) and Abel \& Sander (forthcoming). Our estimated flow tables serve as baseline data for the bi-region population projection model discussed in Section 4. In Section 5, we outline how scenarios for

\footnotetext{
${ }^{2}$ Note that many of the people included in this count are "statistical migrants," such as ethnic Russians living in former Soviet Republics. These people became foreigners not because they moved but because the nation of their birth ceased to exist. Another large share of the world's foreigners consists of displaced persons fleeing civil violence or natural disaster. Such people generally lack the resources to migrate internationally and proceed instead to the closest safe haven, usually within their own or an adjacent country. Leaving aside statistical migrants and displaced persons, only about $1.5 \%$ of the world's foreigners are immigrants in the conventional sense-people who emigrated deliberately as part of a conscious strategy to enhance well-being.

${ }^{3}$ All figures come from the UN's International Migrant Stock: 2008 Revision, available at http://esa.un.org/migration/. Last accessed August 15, 2012.

${ }^{4}$ As a result of this relevance, ignoring the addition or subtraction of population due to migration can distort traditional calculations of net reproduction rates in both sending and destination countries (Ediev et al., 2007; Preston and Wang, 2007). Under some circumstances, emigration and immigration can also have a significant effect on the age structure of a nation (Coleman, 2002; Espenshade, 2001; Keyfitz, 1971).
} 
the projection model are constructed. This includes details on how expert views expressed in an online survey and meta-expert meetings were combined with the baseline data estimates to develop three future migration scenarios. Section 6 sets out the medium scenario and two alternative 'what-if' scenarios derived from expert judgement. Selected results of the population projections regarding projected numbers of migrants and different spatial scales are presented in Section 7.

\section{Migration Forces}

For this paper's scenario-based approach, it is important to consider what kinds of forces have affected migration in the past and might in the foreseeable future. ${ }^{5}$ We classify these in a relatively straightforward manner distinguishing between economic, demographic, migration policy, environmental, and political factors, although migration, as noted previously, is the outcome of interaction among these factors, such that distinguishing the relative importance of each force is often difficult. ${ }^{6}$ Before that, we introduce a more general overview of the volume of international migration flows.

\subsection{The Geography and Timing of the Initiation of International Migra- tion Flows}

As mentioned earlier, international movement seems to be mainly motivated by economic forces. Although the commonplace idea of an international migrant is one moving from less developed to more developed countries, the magnitude of "North-North" and, especially, "SouthSouth" movement has increased in recent decades. Scholars estimate that "South-South" movement may be larger than (or at least, almost up to par with) "South-North" movement (Bakewell 2009; Ratha and Shaw, 2007). Examples of this movement include that of Nicaraguans to Costa Rica (Gindling, 2009; Lundquist and Massey, 2005); Haitians to the Dominican Republic (Grasmuck, 1982); Bolivians and Paraguayans to Argentina (Aide and Grau, 2004; Parrado and Cerrutti, 2003); Bangladeshis to India and Filipinos to Malaysia (Sadiq, 2009); as well as

\footnotetext{
${ }^{5}$ While this overview may also be useful for informing and guiding other forms of forecasting in theory, taking them into account in practice is generally extremely difficult (and, oftentimes, counterproductive) given the difficulty in itself in forecasting economic, social, political, and environmental change at both national and global scales.

${ }^{6} \mathrm{We}$ present these forces (as opposed to a review of theories) because the migration response to these forces could be consistent with several theories in non-mutually exclusive ways. Further, it may be less problematic to assume that a given force (e.g., wage differentials) may continue to have an effect on migration in the future than to assume that a whole theory (i.e., the combination of a set of forces acting in a particular way, such as the notion that wage differentials net of a specific set of migration costs) will continue to have a similar effect on migration in the future.
} 
cross-border labour migration to South Africa (McDonald, 2000). ${ }^{7}$

Uneven processes of development, in their broadest sense, are at the core of factors that explain the initiation of large international migration flows between two given countries. Differences in living standards between sending and destination areas suggest that economic conditions have a preponderant role in stimulating international migration in most corridors, including those with large amounts of intra-regional "South-South" migration (Clark et al., 2004; Massey et al., 1998). Yet, "pioneer" migrants move and choose their destinations not only on the basis of where they can achieve the largest present net wage gains; the establishment of most migration "corridors" is clearly facilitated by prior relations of trade and exchange. That is, although substantial wage differentials generally are a necessary condition for jumpstarting sizable international movements, wage disparities alone are not a sufficient driver of movement. As suggested by the fact that the poorest people from the poorest countries are generally not the most likely to migrate, nor those moving go to the richest nations necessarily, many other economic and non-economic factors play a role in influencing the timing and geography of international migration flows. ${ }^{8}$

For instance, several kinds of active private and public recruitment efforts have set in motion corridors such as Turkish migration to Germany (Abadan-Unat, 1995); Mexican migration to the US (Calavita, 1992); Puerto Rican migration to the continental US (Duany, 2011; Rivera-Batiz and Santiago, 1996); Caribbean migration to Britain, France, and the Netherlands (Grosfoguel, 1997); Middle Eastern, South Asian, Indonesian, and Filipino migration to the Persian Gulf (e.g., Ling, 1984); and ethnic Japanese migration from Brazil, Peru, and Colombia to Japan (e.g.,Tsuda, 2003). All of these flows increased only after recruitment took place, despite the fact that persistent income differentials between these sending and destination areas existed well before recruitment began.

In addition to the timing, the choice of specific countries where to recruit from (and, thus, the pairing of particular sending and destination areas) was further structured by historical connections between places. The labour-importing countries directed recruitment efforts to the less developed nations mentioned above not only because of mere propinquity (which played a role in the Mexico-US case, but only after railroad networks connected the Southwestern US with Central-Western Mexico, (Cardoso, 1980)), but due to colonial (CaribbeanBritain/France/Netherlands, Algeria-France) and cultural/religious ties (Middle East/South/Southeast Asia-Persian Gulf, ethnic "return migration" from Latin America to Japan).

In flows where active recruitment was not at play, similar kinds of translocal and transna-

\footnotetext{
${ }^{7}$ Note, however, that bilateral migrant stocks within developing countries had risen by 1990 but have flat-lined since then. The big rise since 1970 was in developing country migrants in developed countries (Özden et al., 2011, Figure 1).

${ }^{8}$ While this may not be convincing evidence against the power of wage differentials per se, it does suggest at the very least that other factors mediate the role of wage disparities (for instance, by entering the migration decision as costs, (Todaro and Maruszko, 1987)). As such, one of course needs to understand these other factors.
} 
tional connections had a role in influencing the initiation of migration flows and their timing. For instance, military interventions in Southeast Asia explain the beginning of migration from these countries to the US (Rumbaut, 1994). US involvement in Latin America and the Caribbean also explains flows from countries such as the Dominican Republic (Grasmuck and Pessar, 1991), Cuba (Duany, 2011), and Nicaragua (Lundquist and Massey, 2005), among others (see Mitchell, 1989).

\subsection{The Continuation of Migration Flows}

Whatever the original motivation for international migration, it tends to set in motion a series of social and economic changes in both sending and receiving societies that facilitate migration and make additional migration more likely. For instance, international migration is facilitated by different institutions and "industries" facilitating either legal or "irregular" movement (e.g., Spener, 2009). Particularly deep transformations of place lead to a process known as cumulative causation (Massey, 1990). The translocal, transnational exchanges associated with the migration process change life in sending and destination areas in many ways (e.g., Levitt and Lamba-Nieves, 2011; Levitt, 1998), some of which motivate migration even after the conditions originally motivating migration are mitigated (for a more detailed account of cumulative causation processes, see Massey et al., 1998: Chapter 2). One of these mechanisms takes place when migrants remit to their families or bring back large amounts of money that help shift the income distribution of sending areas, motivating the subsequent emigration of individuals from "nonmigrant" households in the wake of their newfound relative deprivation (Stark and Taylor, 1991). Another process of cumulative causation is related to the creation of a "culture" of migration that perpetuates mobility by making it a rite of passage (e.g., Kandel and Massey, 2002).

The most powerful form of cumulative causation appears to be social capital formation, which occurs through the progressive expansion and elaboration of migrant networks. Social capital is created within a migrant's social network whenever he/she gains access to employment in a high-wage country. Friends and relatives thereby acquire a tie to someone who can lower the costs of movement and overcome the barriers to entry, thus increasing their likelihood of migrating (e.g.,Massey and Aysa-Lastra, 2011). Each new departure from the source country expands the migrant network further, creating more social capital that prompts others to emigrate, further expanding the network and creating more social capital, particularly in the context of labour migration and under relative favourable economic conditions in destinations. Under these circumstances, migrant networks can sometimes operate as informal recruitment mechanisms for employers (Krissman, 2000), linking the processes with labour demand and economic development. After this brief overview of how migration flows initiate and continue, let us know turn to discussing the different types of forces and drivers associated with interna- 
tional migration flows more in detail.

\subsection{Economic Forces, Development, and Emigration}

International migration is mostly driven by economic development and the penetration of markets into non-market societies. The creation of markets for land, labour, and capital, the mechanization of agriculture, and the industrialization of production powerfully transform societies, displacing large numbers of people from more "traditional" ways of life in the process. The entry of nations into the global regime of trade, production, and exchange thus creates populations of people highly motivated to look for new ways of securing their material well-being. Economic development, at least in its early stages, may produce rather than inhibit migration (Sassen, 1998).

Under conditions of economic transformation, international migration becomes an "attractive" strategy that people can deploy in order to adapt to changes set in motion by globalization and development. In the absence of international recruitment, most of those displaced by market penetration may move within their own countries, either to urban destinations or to rural areas with commercial primary sector production. Those who do move internationally are either highly selected with respect to risk-taking, ambition, and motivation or have access to forms of capital that can support and facilitate an international move, including the social capital discussed in the prior section.

In seeking to move internationally, migrants adopt one of two basic economic strategies. Those with access to human or financial capital seek to maximize material well-being by relocating to a more affluent nation in search of higher wages (Todaro and Maruszko, 1987) and greater returns to capital. These moves tend to be permanent, or at least of longer durations, and often involve the "tied" migration of dependent family members (Cerrutti and Massey, 2001; Zlotnik, 2005). The costs and barriers to international movement are lower for those with access to human or financial capital, as many nations have policies to encourage the entry of skilled, educated, and wealthy immigrants.

Apart from maximizing earnings, another motivation for international migration is to overcome the nonexistence or malfunctioning of markets at places of origin (Stark and Bloom, 1985). By sending family members to work in high wage countries, households can also generate remittance streams to smooth consumption in the absence of credit markets, accumulate savings to fund investments in the absence of capital markets, and overcome capital and crop losses in the event of climatic variability in the absence of insurance markets. By sending different family members to different geographic locations, households can also self-insure against other risks to income (e.g., due to unemployment) by diversifying their labour portfolios and generating multiple earnings streams.

Whereas a migration strategy aimed at maximizing individual earnings may suit skilled 
workers who move for purposes of settlement or long-term employment, migration decisions in the wake of market failure and volatility in sending areas are oftentimes temporary and collective, involving households sending out unskilled workers for shorter periods of foreign labour to generate funds that can solve economic problems at home. This latter motivation seems to predominate in many international flows (Massey et al., 1998), perhaps partly as it responds to several forms of economic, social, and environmental change.

\subsection{Migration as an Adaptation Strategy to Climate and Environmental Change}

The effects of environment and environmental change are complex (Hugo, 1996) and mediated not only by the severity and nature of environmental change but also by the vulnerability, resilience, resources and situation of impacted communities. As a whole, research on the environmental drivers of migration suggests that environmental factors act in concert with socioeconomic, political and cultural considerations to shape migration decision-making (e.g. Black et al., 2011). In some cases, environmental scarcity may constrain some types of mobility (e.g., Gray, 2009) since natural resources provide the capital necessary for livelihood diversification (e.g., Nawrotzki et al., 2012). ${ }^{9}$ Overall, short-distance mobility is typically more common than international movement among drought- and/or poverty-stricken populations (e.g., Gray and Mueller, 2012; Henry et al., 2003).

Stojanov (2008) has classified environmentally induced migrations according to the nature of their causes, distinguishing between environmental migrations initiated by dramatic and sudden environmental events such as tsunamis, hurricanes and volcanic eruptions, and those of slow onset, with gradual but cumulative environmental forces. This is an important distinction since both the mobility responses and the policies relating to them are different. ${ }^{10}$ Sudden disasters can be very destructive and cause major displacement of population but that displacement is usually temporary. For instance, most people displaced by the Asian Tsunami of 2004 eventually returned and rebuilt their communities (Laczko and Collett, 2005). Indeed, the influx of resources and the magnitude of the task of rebuilding can lead to an immigration of additional workers (Laczko and Collett, 2005). In contrast, migration associated with slow-onset environmental change can be much more varied, because residents of areas affected by this kind of deterioration are generally able to deploy a larger variety of in situ adaptations.

Yet, specific types of migration may indeed take place in response to slow-onset environmental change, particularly if this in situ adaptive capacity worsens. For instance, a common

\footnotetext{
${ }^{9}$ Access to productive land also positively predicts out-migration in some settings (e.g., Gray, 2009; VanWey, 2005).

${ }^{10}$ The sudden environmental hazard impact attracts most attention among policy makers and researchers, while the latter has been neglected, particularly with regards to international migration (see Hunter et al., forthcoming).
} 
initial response to perceptions of food shortages associated with environmentally-induced crop failure is temporary circular migration of some of a family's labourers to work in areas not affected by the famine, such as cities. If the famine is prolonged and it becomes unsustainable to remain in the area, this gradually gives way to displacement of entire families on both temporary and permanent bases. In extreme cases, where the entire food resources of an area are exhausted, the result may be mass distress migration (Black et al., 2011).

Drought has dramatic impacts on livelihoods, especially in rural, agriculturally dependent regions such as northern Africa. Yet, evidence suggests that on-going adaptation through livelihood diversification often reduces rural household vulnerability. In northern Ethiopia, for example, households with more diverse livelihoods involving animals, non-agricultural income, and/or migrant remittances have more options for coping with drought. Still, there seems to be a threshold above which rainfall deficits force even diversified peasant households to migrate (Meze-Hausken, 2000). Similarly, residents of dry regions of Burkina Faso are more likely to engage in both temporary and permanent migrations (Henry et al., 2003), perhaps related to diversification of origin incomes through remittances.

Historical research in the US Great Plains also links early 1900s outmigration to rainfall deficits in agriculturally dependent regions and in periods of particularly poor weather (Deane and Gutmann, 2003; Gutmann et al., 2005). Indeed, migration has long been a human strategy in the face of climate constraints, with some scholars making use of historical analogues to consider future climate impacts (McLeman and Hunter, 2010; McLeman and Smit, 2006).

As mentioned before, some types of moves (urban-oriented, short distance, internal) may be more likely to take place under these conditions. Although it has been argued that many of the processes shaping internal and international migration are similar (King and Skeldon, 2010; Skeldon, 2006), the fact remains that the controls exerted over migration between countries are much greater than those within countries. Internal migration is usually a more available option than international migration, involving smaller distances, lower costs, ease of travel, and less economic, social and cultural disruption. Accordingly, in most contexts the rates of internal migration are greater than international movement (Bardsley and Hugo, 2010).

International migration is a much less likely response to these kinds of environmental forces. Migration across national boundaries is not an easy undertaking - and resource scarcity may inhibit costly diversification strategies. For example, people in dryer regions of Burkina Faso were less likely to emigrate to international locales (Henry et al., 2003). Yet, international migration can be a response to environmental stress in some circumstances, in the presence, for example, of pre-established international migrant networks. This is the case in rural Mexican communities with a longstanding history of migration to the US, where rainfall deficits are associated with higher international migration (Hunter et al., forthcoming). Still, "climaterelated migration" out of these Mexican communities seems to be an exception to a pattern of low international out-migration in the wake of slow-onset environmental change. 
The increased focus on environmental drivers of migration has stemmed largely from the recognition that human-induced climate change is one of the most significant global challenges of the twenty first century. Part of the burgeoning global discourse on climate change has focused on its potential effects in displacing populations. While it has long been recognised that changes in environmental conditions can have an important effect on migration (Hugo, 1996), this relationship has been oversimplified in much of the recent discourse on the impact of climate change. Much of this discussion assumes that there is a simple deterministic effect whereby environmental change results inevitably in population displacement. For example, the most authoritative Fourth Assessment of the Intergenerational Panel on Climate Change (2007) stated:

"Stresses such as increased drought, water shortages and riverine and coastal flooding will affect many local and regional populations. This will lead in many cases to relocation within and between countries, exacerbating conflicts and imposing migration pressures".

Accordingly, there have been a number of "projections" of future population displacement that largely assume all people in areas severely impacted by climate change will move. Hence there are pronouncements, which have been given wide currency, that climate change and especially associated sea level rises will result in the displacement of hundreds of millions of people between countries (Christian Aid, 2007; Myers, 2002). These "projections" are not based on a detailed analysis of future trends in climate patterns (McLeman, 2011), nor on an understanding of drivers of migration (Bardsley and Hugo, 2010). The reality is that the relationship between migration and environmental change is complex, and that this complexity must be taken into account in any assessment of future effects of climate change on migration.

\subsection{Shocks to the System? Violence, Political Upheaval, and Displace- ment}

Shocks are extreme disturbances that affect social systems. In addition to the types of suddenonset environmental events discussed above, dislocation associated with war and political turmoil can cause vast population displacements out of conflict zones, including refugees. These more forced migrations oftentimes take place against a backdrop of more voluntary movement undertaken for reasons related to work, family, education and retirement. In this subsection we provide a brief outline of international political events and conflicts that have generated migrant flows around the world.

At the global level, the 1960-to-2000 time series of inter-country migration indicate a great deal of politically generated migration. The United Nations High Commissioner for Refugees (UNHCR, 2012) estimated that at the end of 2010 there were an estimated 33.9 million people 
"of concern". These included 10.6 million refugees, 838 thousand asylum seekers, 14.7 million internally displaced persons protected or assisted by UNHCR, 3.5 million stateless persons and 1.3 million others. As the focus of this paper is on international movement, we do not focus on internal displacement that is common in conflict situations, which (as the figures above suggest) is in many cases more common than refugee outflows (also see International Displacement Monitoring Centre (IDMC), 2013).

Domestic and international conflicts in North Africa and West Asia have been numerous. Since 1960 there have been wars involving Afghanistan (1979-1989, 2003-2012), Algeria (1954-1962), Iraq/Iran (1980-1988), Iraq/Kuwait/US coalition (1990-1991), Iraq/US coalition (2003-2011), Israel/Jordan/Egypt/Syria (1967), Israel/Lebanon (1982-1985, 2006), Libya (2011), Syria (2012), and Yemen (1994). These conflicts all generated political refugees, several millions in the case of Afghanistan. It is likely that violence will continue in the decades ahead as the political, religious, and ethnic divides continue to be sources of conflict.

In South Asia, massive international movement was spurred by population exchanges between India and Bangladesh around the secession of East Bengal from Pakistan; by the India/Pakistan wars; and by the decades-long Tamil-Singhalese conflict in Sri Lanka. Southeast Asia saw a quarter century of war (roughly between 1950 and 1975) in Vietnam, Cambodia, and Laos leading to large refugee flows into the United States and Europe (Rumbaut, 1989). In Burma/Myanmar the civil war between the military and ethnic minorities has persisted for decades, leading to the emigration of several thousand people to neighbouring Thailand (Lang, 2002). East Asia experienced large refugee flows during the Korean War.

West Africa has seen civil wars in Nigeria, Sierra Leone, Ivory Coast, Mali and Liberia. Central and East Africa have seen decades of conflict in the Congo, Rwanda, Burundi, Uganda, South Sudan, and Sudan. Southern Africa has experienced refugee flows as a result of wars of independence in Mozambique and Angola, and consequent to the economic collapse in Zimbabwe. Latin America has also experienced civil wars displacing people out of Guatemala, El Salvador, and Nicaragua (Coutin, 2003; Lundquist and Massey, 2005), as well as a large exodus of political refugees from Cuba (Duany, 2011). Most of refugees from Latin America relocated in the US.

Europe also saw large refugee flows during the 20th Century, including the massive movement of people during both World Wars and the exodus of individuals of Jewish descent out of Eastern and Central Europe. During the Cold War, refugees trickled out of Warsaw Pact nations, with larger outflows observed in times of unrest, such as in Czechoslovakia (1968) and Poland (1980-1989). Although the breakup of the Soviet Union and the fall of the Iron Curtain, a structural break that was a shock to the political and social systems, did not lead to major refugee flows per se, it did greatly facilitate the migration of Eastern and Central Europeans of Jewish descent to Israel and of ethnic Germans (Aussiedler) into the newly reunified Germany. In addition to the relocation of Russians, Kazakhs, Uzbeks, and people from other former So- 
viet Republics back to their ethnic/national homelands, several million of them were classified as international migrants by virtue of the breakup of the Soviet Union and their location in a country different to their ethnic/national homeland (Zlotnik, 1998: p. 446-449).

Unfortunately, it is expected that these flows will continue in the future as turmoil continues in much of the world. This complicates projection exercises as it is indeed difficult to forecast international flows that include a nontrivial component of movement related to conflict and other types of shocks, not only in terms of magnitude, but also in terms of timing and directionality. Yet, with hardened refugee and asylum policies around the world, it is likely that many displaced individuals will not leave their countries of origin but will be increasingly classified as internally displaced (hopefully while still protected by organisations such as UNHCR). Since 1951, the asylum regime has gone through several global policy shifts, giving preference to third-country resettlement to the US, Canada, and Australia until the late 1950s; integration in the country of first asylum or voluntary repatriation from the 1960s to 1980s; and preventing refugee flows from occurring or confining them to their region of origin since the 1980s (Crisp, 2000). We now turn to policies influencing different forms of immigration flows, where we also discuss asylum policies.

\subsection{The Effects of Migration Policies on Migration Dynamics}

Political theorists and migration scholars have posited that the ability to exert control over a bounded territory and determine who is allowed to enter and remain in it is one of the foremost defining features of a state (Gibney, 2004; see also Haddad, 2003; Held, 1995; Zolberg et al., 1989). Broadly conceived, policy is one of the most important barriers to and facilitators of migration. For instance, intra-regional movement has been facilitated by bilateral and regional agreements allowing the free movement of people, such as in the case of the European Union and envisaged and currently underway for the Economic Community of West African States and the East African Community. Yet, movement to and from nation-states may be affected not only by migration policies, but also by what Czaika and de Haas (2011) term "non-migration" policies. Migration policies are laws or regulations that have the express aim of regulating the size and structure of migration flows, such as the British Alien Act of 1844 or Uganda's Control of Alien Refugees Act of 1960. Non-migration policies are laws and regulations that carry no such direct (or even intended) aim, but nevertheless impact the size or structure of migration flows because they influence migration determinants, such as the United Kingdom's Welfare Reform Act 2010-2012 (Czaika and de Haas, 2011; Haddad, 2003). ${ }^{11}$

Non-migration policies may have a greater effect on migration flows than migration policies

\footnotetext{
${ }^{11}$ The line between migration and non-migration policies is at times difficult to draw, for laws regarding citizenship or labour market policies may have elements that seek to address migration issues (Czaika and de Haas, 2011).
} 
in terms of magnitude and long-term trends, as they may be linked to structural determinants of migration, such as macro-economic and political conditions (e.g., labour demand in countries of destination; social and development policies in sending areas). Migration policies, on the other hand, target specific aspects of migration and categories of migrants (Czaika and de Haas, 2011, p. 5). The effects of such policies on flows are easier to evaluate than the effects of non-migration policies.

The effect of a migration policy can be ascertained by its effectiveness in influencing the size or composition (e.g., gender, nationality, age, education, skill distribution) of migration flows. Migration policies can affect migration in both intended and unintended ways. Typically, if a migration policy yields an unexpected outcome, it is because 1) the policy interacted with powerful non-migration policies or macro-level migration determinants in ways unforeseen by policymakers, 2) the policy was comprised of contradictory and self-undermining aims, or 3) a gap existed between the discourse surrounding the policy and the actual policy measures and the implementation of the policy (Czaika and de Haas, 2011; Ellermann, 2006).

De Haas (2011) posits there are four types of unintended migration policy effects or "substitution effects": spatial, categorical, inter-temporal, and reverse flow. Spatial substitution refers to migration flows diverted to other locations, rather than being disrupted, as in the case of Chinese migrants "diverting" into the North-West of Mexico and other parts of Latin America at the advent of the 1882 Chinese Exclusion Act in the US (Lee, 2003, p. 157). Categorical substitution occurs when migrants shift to different legal or unauthorized migration channels after a particular channel is targeted by control policies, as in the interplay between overstaying tourist visas and crossing borders without authorization. Inter-temporal substitution occurs when migrants anticipate a tightening of migration policies, prompting them to migrate en masse, as in the 1980 Mariel boatlift out of Cuba (Duany, 2011). Lastly, reverse flow substitution takes place when return migration flows decrease as a result of increasing migration restrictions, as with the decreasing return rates of undocumented Mexicans in the aftermath of increased U.S. border enforcement in the 1990s (Angelucci, 2012; Reyes, 2004).

Before exploring specific types of migration policies and their effects, it is important to acknowledge that although migration policies can have an observable impact on migration flows, they are not an independent migration determinant. Rather, migration policies are, to some degree, endogenously determined by prior migration flows and can reflect existing migration patterns, which are in turn affected by the effectiveness of past migration policies.

\subsubsection{Immigration Policies}

The empirical literature on the effects of immigration policies suggests that restrictive immigration policies reduce the flows of people, and more generally that migration policies affect migration flows in the intended "direction," but not necessarily in the fully intended manner (Czaika and de Haas, 2011, p. 17; see also Green and Green, 1995; Mayda, 2010; Ortega 
and Peri, 2009). Additionally, the effects of structural migration determinants in sending or receiving countries in constraining or promoting migration are larger when coupled with more restrictive or open immigration policies, respectively. Hence, the positive effect of increasing GDP per capita on immigration flows is more pronounced during times of relatively open immigration policies. Compared to macro-level migration determinants like economic growth, labour demand in receiving countries, conflict, or youth cohort size in sending countries, immigration policies appear to have a small effect on flows, particularly on undocumented, "illegal," or irregular migration (Angelucci, 2012; Cornelius and Salehyan, 2007; Czaika and de Haas, 2011; Spilimbergo and Hanson, 1999).

\subsubsection{Asylum Policies}

The right to seek asylum from persecution was established in the Universal Declaration of Human Rights in 1948 and formed the basis of the 1951 Refugee Convention. At its core, this right allows any non-citizen to enter a territory, either through authorised or unauthorised channels and apply for asylum without the threat of being forcibly returned to his or her country of origin before a status determination is made and before it can be established that the non-citizen would not return to cruel or inhuman treatment. Although the concept of asylum from persecution is established in international law, some states and regions have adopted more expansive asylum policies that include generalised violence and individuals fleeing conflict (see the 1969 OAU Convention and 1984 Cartagena Declaration). Furthermore, while the right to seek asylum from persecution is well-established, the right to settle in a country is not.

As a result, states and regions uphold the right to asylum and settlement through their own policies and procedures, including status determination waiting periods, resettlement quotas, detention practices, and welfare benefits. Thus, it is possible to observe the effects of different asylum policies on migration flows. For example, some studies have found that increasingly restrictive asylum policies in Europe have reduced immigration flows (Hatton, 2004; Holzer et al., 2000; Thielemann, 2005). In contrast, it is unclear in the US whether the tightening of asylum policies reduced immigration or only pushed flows into irregular forms of movement (e.g., Coutin, 2003).

\subsubsection{Emigration Policies}

In examining the impact of policies on migration, few studies explore the effects of policies designed to control emigration or of non-migration policies issued by "sending" countries (de Haas and Vezzoli, 2011; Kureková, 2011). Emigration policies that encourage or restrict emigration often aim to control the migration of specific groups of individuals, based on gender, skill level, education, or ethnic affiliation. We know of no empirical studies of the effects of these policies on contemporary migration flows (de Haas and Vezzoli, 2011; Fitzgerald, 2009; 
Kureková, 2011), perhaps because of the tendency in the literature to emphasize other forms of immigration; the lack or low quality of emigration data; the relatively small amount of emigration policymaking as compared to immigration; and the fact that the right to leave one's country is internationally recognised.

\subsection{Socio-demographic Factors}

Demographic factors that can affect the level of migration include not only the size and growth rate of the population per se but its age and sex structure, all of which are the expression of past demographic rates (e.g., Preston et al., 1989). There are two main types of migration related to demographic factors. The first refers to how population growth and, especially, age structure imbalances influence relative labour supply and labour migration patterns. The second relates to how the age-sex structure of the population shape marriage markets and stimulates marriage migration.

\subsubsection{The Demography of Labour Demand and Supply as Drivers of Labour Migration}

High population growth rates resulting from high fertility and low mortality rates lead to a young population and, potentially, to excess labour supply, which can increase unemployment rates and curb wage growth. A large cohort of people in the mobile young adult ages is a potential source of migrants (e.g., in the case of Mexico - U.S. migration, see Hanson and McIntosh, 2010), particularly when sending nations face challenging economic or political conditions (e.g. Coleman, 1993), although the lack of development per se does not necessarily yield the highest emigration rates.

By the same token, slower population growth, stability or decline, when combined with the appropriate structural and institutional conditions, can also affect migration and even lead to immigration. Fertility decline and slower population growth lead to fewer young people in the mobile age groups, thus reducing the supply of potential emigrants. Some former migrantsending nations, mainly in East and Southeast Asia and South and Western Europe, have undergone this kind of demographic transition while also having solid social, political, and economic institutions and experiencing high economic growth and expansion due to investments in human capital and infrastructure (Bloom and Canning, 2008; Paldam, 2003).

This prosperity might have not only led them to reap fiscal and economic benefits of having a population heavy in the middle-age groups, but could also explain their transition from sending 
to receiving nations. ${ }^{12}$ Population and labour force ageing can result in a shortage of workers, which is most likely to be felt in the service sectors. Countries experiencing a short supply of either skilled or unskilled labour have turned to importing labour from other countries with a more abundant supply of workers (Piore, 1980). For example, labour demand and supply issues have been important drivers of Australia's immigration program since the 1950s and in the current context of below replacement fertility rates since the 1980s. Labour issues will continue to be important drivers of immigration policy with the impending retirement of the baby boom cohorts in the next two decades (McDonald and Temple, 2008).

The likelihood of population decline in industrialised countries with very low fertility rates has led the UN Population Division to project the scale of migration needed to prevent population decline, to maintain a constant population in the working ages, and to maintain a constant ratio of older persons to persons of working age (United Nations, 2000). These projections are illustrative of the role of demographic factors as drivers of migration if countries decide to consider migration as a policy instrument for addressing the issue of future population and labour force declines (see also Coleman, 2002; Espenshade, 2001).

\subsubsection{Socio-demographic Drivers of Marriage Migration}

Demographic factors can also affect the availability and choice of marriage partners, stimulating cross-border marriage migration. The sex ratio of the population in the marriage ages is a function of changing fertility, sex-selective mortality and migration in younger ages, and imbalances in the sex ratio at birth. In most societies, men usually marry younger women. In a population experiencing declining fertility rates, the size of younger cohorts of women would be smaller than those of older cohorts of men, implying that some of these older men may have difficulty finding a spouse in the "appropriate age group". Demographers refer to these circumstances as a "marriage squeeze." Advances in female education and other social and cultural factors affecting people's preferences in the choice of a marriage partner can exacerbate the problem.

In addition, the contemporary increase in sex ratios at birth in several Asian countries (e.g., Coale and Banister, 1994; Guilmoto, 2007), to figures well above the "normal" ratio of 103-107 male per 100 female births (e.g., to 110-117), also has the potential to exacerbate the problem in future. A marriage squeeze can lead to men looking abroad for potential marriage partners (Davin, 2007; Guilmoto, 2007), particularly when cross-border marriage migration is facilitated

\footnotetext{
${ }^{12}$ Demography may have a role in the current status of China and India as two of the top source countries of migration. These two most populous countries in the world currently have a relatively large proportion of people in the peak migration age groups and have emerged as significant sources of migrants to countries such as Australia, Canada and the US. They have been the largest sources of immigrant arrivals in Canada since 1996 (Statistics Canada, 2006); the first and third largest sources of immigrants to Australia in 2010-11 (Department of Immigration and Citizenship, 2011); and the second and third largest sources of legal permanent resident admissions in the US (Office of Immigration Statistics, 2010).
} 
by cheap transport and communication.

In addition to marriage migration motivated by age-sex structure imbalances, newly established migrant or ethnic communities (which in some cases may have an unbalanced sex ratio in the marriage age groups, such as an excess of young single men) may further stimulate marriage migration from the country of origin if there is a preference for a marriage partner of the native ethnic origin (among the first or second-plus generations) or there are other barriers to intermarriage with local residents, as in the case of some ethnic communities in Australia, Europe and North America (e.g., Telles and Sue, 2009).

\subsubsection{Beyond Drivers: The Relevance of Understanding the Demographic Profile of Mi- grants}

Although demographic factors are generally not the main drivers of international migration flows, it is important to understand them for a better estimation and forecasting of migration. In addition to their mild influence on the magnitude of flows, understanding the composition of migrants and their socio-demographic selectivity is also useful for surmising some of the root causes and potential consequences of migration for sending and receiving areas, and for investigating them further. Given the paucity of detailed data for many immigrant groups, sociodemographic profiles of both emigrants and return migrants have helped scholars understand migration trends, particularly at the regional and global levels (e.g., Fassmann and Munz, 1992; Zlotnik, 1998).

Demographic characteristics can also be useful for the indirect estimation and forecasting of migration, given that many migration flows exhibit relatively stable demographic patterns (Rogers et al., 2010). This is particularly true in the case of age patterns of directional migration flows (e.g., Rogers and Castro, 1981; Rogers et al., 2007), which have remarkable stability, which is also the case in other demographic events. We take advantage of these regularities in our estimations and projections of global international migration flows, as explained in the next Section.

\section{Global Estimates of International Migration Flow Data}

International moves are typically enumerated in a demographic context using a measure of either migrant stocks, defined as the number of people living outside the country in which they were born, or migration flows, defined as the number of persons migrating between two countries over a specific time period. Flow measures reflect the dynamics of the migration process but are harder to estimate and less available than stock measures (Bilsborrow, 1997).

Flow data have several desirable qualities, including a better representation of contemporary patterns and trends than stock data. Flow data provide a quantifiable measure of the number of 
movements over a specified time period required, along with rates of births and deaths, by population projections models. However, detailed flow data required for advanced projection models tend to be available only for more developed nations. In response to this demand, we developed a methodology to estimate bilateral migration flows between all countries. The methodology, fully detailed in Abel (2013) and Abel \& Sander (forthcoming), provides a single bilateral table of migrant transitions from mid-2005 to mid-2010 for each sex. The estimates thus allows additional regularities by age and other factors to be incorporated into the disaggregation of estimated migration flows by age and sex, as required by advanced projection models.

As with other components of demographic change, populations have been found to have considerable regularities in age-specific rates of migration. A typical migration age schedule is shown in the solid grey line in Figure 1.

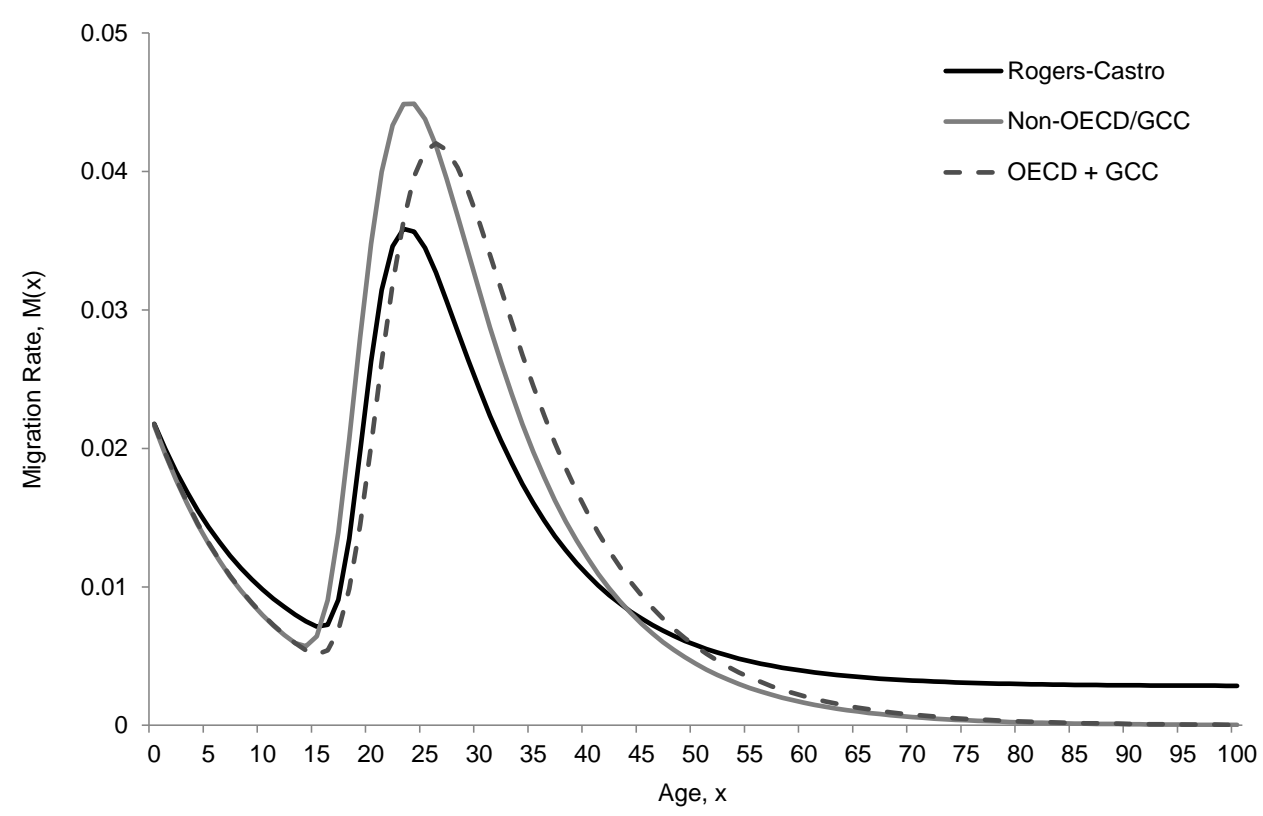

Figure 1: Model Migration Schedules.

Migration rates among infants and young children are relatively high, similar to those of their parents and other young adults in their twenties and early thirties. Migration rates of adolescents are low but exceed those of young teens, for whom the lowest migration rate is about age 15. Rates rise to a peak after the completion of education and then fall monotonically with age to retirement years. Rogers and Castro (1981) proposed a mathematical representation of migration age schedules, $\mathrm{M}(x)$, for age $x$ using 7 parameters;

$$
M(x)=a_{1} \exp \left(-\alpha_{1} x\right)+a_{2} \exp \left\{-\lambda_{2}\left(x-\mu_{2}\right)-\alpha_{2}\left(x-\mu_{2}\right)\right\}+c
$$

The first exponential in the schedule controls the rate of decent in the pre-labour force component. The second exponential controls the shape of the labour force peak. In the first 
half, the exponential, $\lambda_{2}$ term represents the rate of accent in the peak, while in the second half, the $\alpha_{2}$ parameter controls the decent. The $\mu_{2}$ term controls the location of the peak.

Rogers and Castro (1981) proposed a unisexual standard set of fundamental parameter values having separately fitted the schedule to inter-region migration flows in 17 countries and then averaging. Later studies have proposed extensions to the model schedule, adding more parameters to include retirement peaks, post-retirement slopes (Rogers and Little, 1994) and entry into higher education (Wilson, 2010). These values, shown in the first column of Table 1, imply a number of simple ratios between various parts of the age schedule (see Rogers and Castro, 1981 for further details).

Table 1: The parameters of the model migration schedule for the standard Rogers-Castro and our two custom schedules

\begin{tabular}{cccc}
\hline Parameter & Rogers-Castro & Non-OECD/GCC & OECD + GCC \\
\hline$a_{1}$ & 0.02 & 0.015 & 0.015 \\
$a_{1}$ & 0.10 & 0.10 & 0.10 \\
$a_{2}$ & 0.06 & 0.06 & 0.06 \\
$\lambda_{2}$ & 0.40 & 0.30 & 0.25 \\
$\mu_{2}$ & 20 & 20 & 22.5 \\
$a_{2}$ & 0.10 & 0.10 & 0.10 \\
$c$ & 0.003 & 0 & 0 \\
\hline
\end{tabular}

The migration schedule formed by entering the fundamental parameter set parameters into $M(x)$, is plotted in the solid grey line of Figure 1. The estimates from the schedule have been scaled to fix the area under the curve to be unity.

As there was no information on migrant stock populations by age, we were unable to estimate age-specific flows using the flows-from-stock methodology outlined above. In order to derive estimates by age groups, required for cohort component projection models, we relied upon the seven-parameter age schedule of Rogers and Castro to disaggregate each estimated flow in our bilateral table. Given the age-schedules, where the sum of the age-specific migration rates summed to unity, we multiplied through age specific rates at each 5 year interval to each origin-destination-sex $\left(m_{i j s}\right)$ table;

$$
m_{i j s}=m_{i j s} M(x)
$$

This resulted in an array of origin-destination migration flow table by sex and age. What follows in the remainder of this sub-section is an outline of how assumptions for the age-specific rates were set, dependent on the country of origin.

In order to account for differences between internal migration (from which the fundamental 
parameters were derived) and our international migration application, we altered some values of the fundamental parameter set used to derive the age-specific rates, depending on the country of origin. For flows from countries outside the OECD (Organisation for Economic Co-operation and Development) and GCC (Gulf Cooperation Council) countries, we applied a migration schedule with a larger labour force peak, shown in Figure 1. This schedule is based on the parameter set given in the second column of Table 1 , and then scaled to set the sum of the age-specific rates to sum to unity. Only three parameters differ from those in the fundamental parameter set. First, the $a_{1}$ parameter was reduced to lower the relative amount of child migration flows in relation to young adults entering the labour force. Second, the rate of ascent in the labour force peak was lowered to average over differing ages of entrance into the labour force across multiple countries. Third, the $c$ parameter was set to zero, lowering elderly international migration intensities to very low levels.

Flows that originated from OECD and GCC countries were assumed to follow a migration age schedule with a later peak, shown in Figure 1. This schedule is based on the parameter set given in the third column of Table 1 and then scaled to set the sum of the age-specific rates to unity. Two parameters differ from the schedule used for the non-OECD/GCC nations. First, the ascent of the labour force peak is further reduced. Second, the location of the peak is shifted by 2.5 years. Both alterations reflected an assumption of moves after longer periods of education and later entry into the education market in these countries, while also allowing return migration of temporary workers from non-OECD/GCC countries at older ages.

For the new set of global population projections, we extracted from our flow estimates information on the intensity of immigration and emigration for each country in the period 2005-10 disaggregated by age and sex. These immigration and emigration rates serve as the basis for our assumptions about future migration. We present in Figures 2 and 3 the 10 countries in the more developed world (left) and the less developed world (right) with the highest immigration and emigration intensities in 2005-10. Rates were calculated using each country's population in 2005 . 

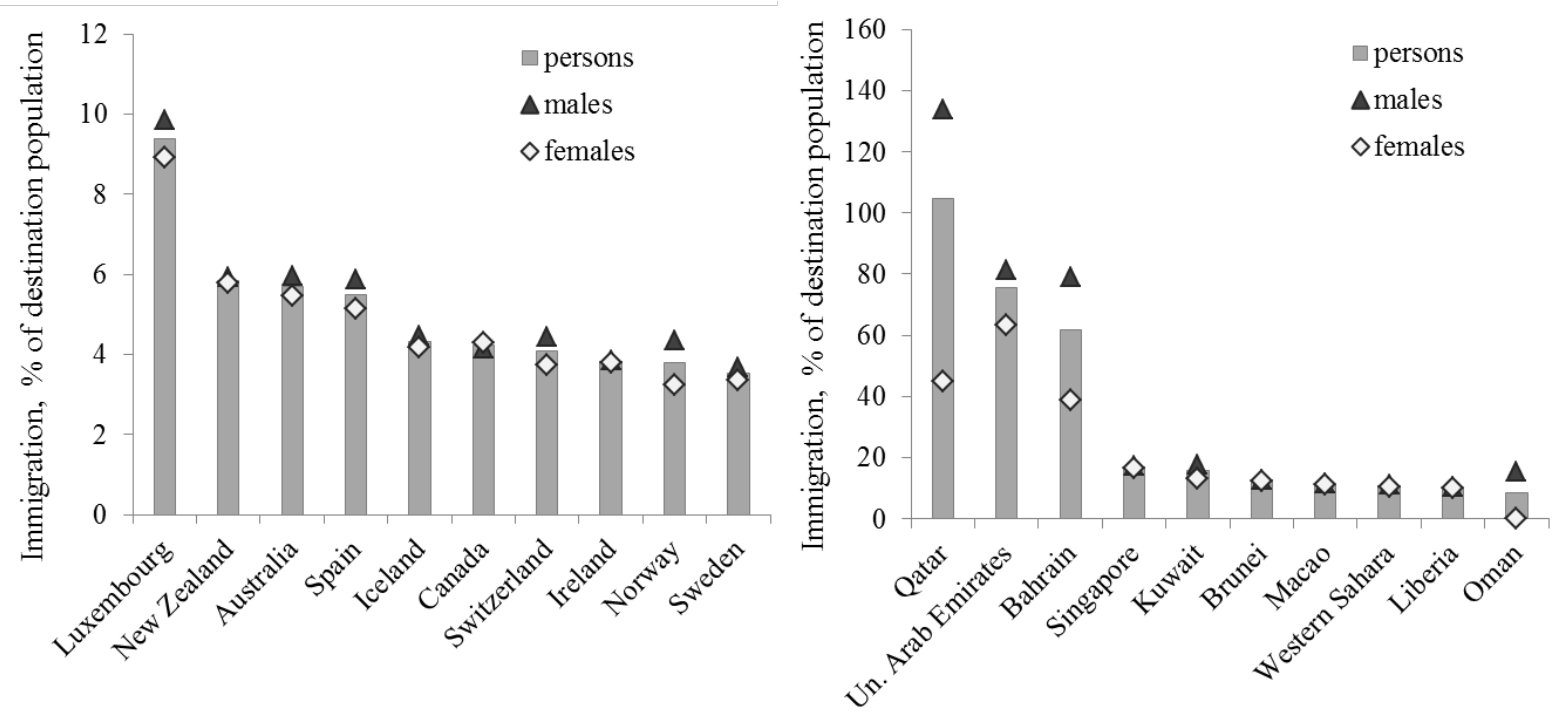

Figure 2: The top 10 immigration countries (in per cent of population) among more developed (left) and less developed (right) countries in 2005-10.

Figure 3 depicts the more and less developed countries with the highest emigration rates in 2005-10. The overall pattern is one of much lower emigration rates compared to the immigration rates shown in Figure 2. Moreover, gender differences are stronger for emigration from more developed countries than from less developed ones (with the exception of Zimbabwe, which records strong male labour migration to South Africa). High intensities of emigration from several eastern European countries (e.g. Moldova, Montenegro, Albania and Serbia) can be expected to accelerate population ageing and decline in these countries. As we discuss in Section 4, the projected size of populations in these countries strongly depends on whether assumptions about future trends are made in terms of absolute numbers of emigrants or in terms of emigration rates. 

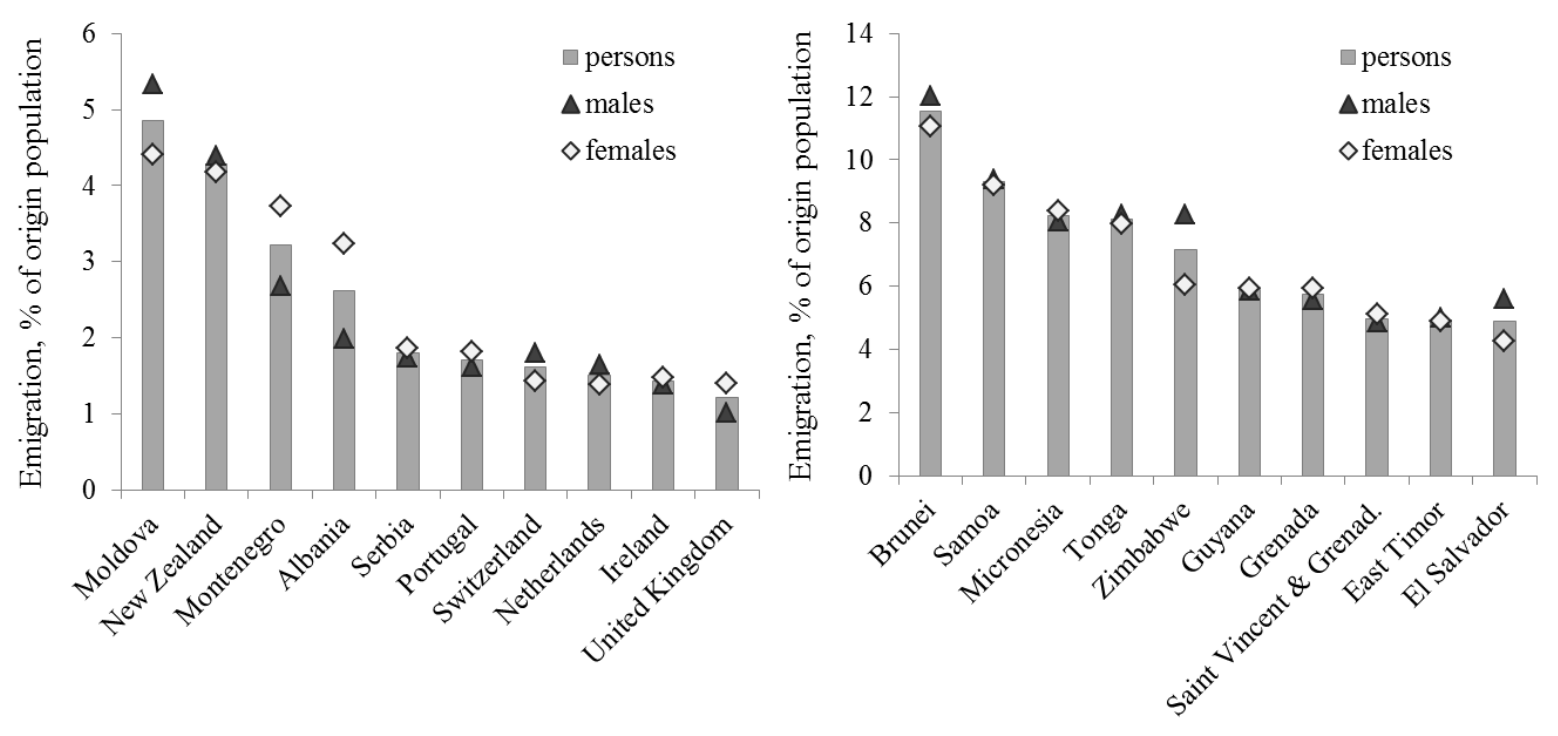

Figure 3: The top 10 emigration countries (in per cent of population) among more developed (left) and less developed (right) countries in 2005-10.

\section{Population Projections Using a Bi-regional Model}

The accurate projection of migration in the long run is one of the most difficult challenges in population forecasting. The high temporal volatility in net migration in many countries, coupled with the lack of adequate bilateral flow data have hindered the application of multiregion flow models (Rogers, 1995) in global population projections. Consequently, the widely used projections published biannually by the UN use simplistic assumptions of net migration measures derived as residuals from demographic accounting. However, net migration numbers are known to introduce inaccuracies when projecting populations (Raymer et al., forthcoming; Rogers, 1995; Wilson and Bell, 2004).

The global population projections presented in this volume depart from the common practice of focusing on a convergence of net migration rates towards zero. Instead we apply a multiregion projection model to forecast global population. The baseline migration data for the projection model are obtained from the application of a methodology to estimate global bilateral flow tables from known migration stock totals detailed in Abel (2013) and Abel \& Sander (forthcoming).

Multi-regional projection models are frequently used in sub-national projections (Wilson, 2011). Rather than projecting each country-to-country flow, we use the bi-regional model as a spatial aggregation of the full multiregional framework (Rogers, 1995). In the bi-regional setting, each country in the world is handled in turn. Migration to and from each country is projected by dividing the world into the target country and the rest of the world (see Figure 4). Then, international migration flows from the target country (here: USA, then Canada) to 
the rest of the world, and vice versa, are projected. While yielding results that are similar in accuracy to the multi-region model, the bi-regional version requires much less input data and fewer assumptions (Raymer et al., forthcoming; Wilson and Bell, 2004).

To take into account the effects of population ageing and decline on migration intensities, our migration assumptions correspond to probabilities rather than absolute numbers. The assumption of constant probabilities rather than constant absolute numbers of migrants can over time produce changes in the absolute flows as a function of changing national population size (for emigration), or world population size (for immigration). Using a transitions framework, we compute emigration probabilities in 2005-10 using the origin population in 2005, conditional upon survival to 2010. Immigration probabilities for a given country are calculated using the population in the rest of the world in 2005, conditional upon survival to 2010. Directional migration flows are then projected as the product of migration probabilities and the population in the origin (for emigration) and the rest of the world (for immigration). As with all bi-regional models, a small adjustment is made at each five-year projection step to ensure that total emigration across all countries equals total immigration.
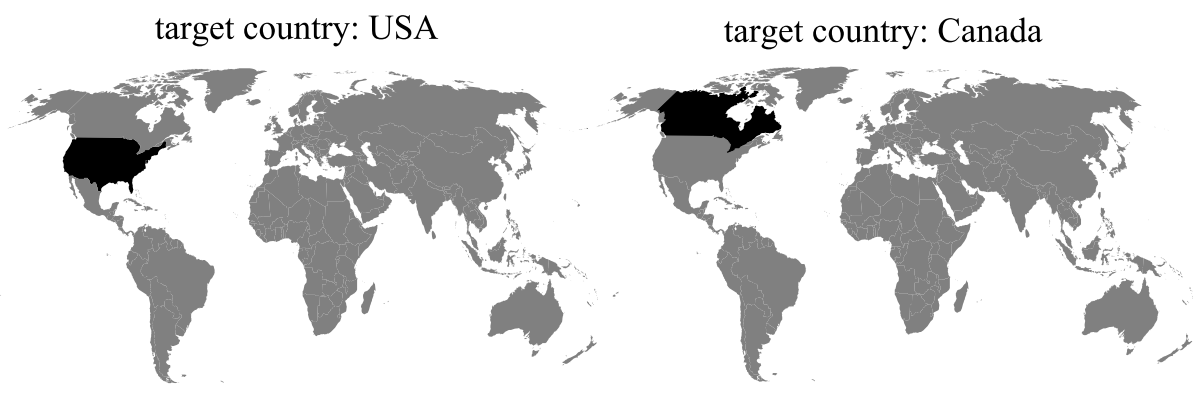

Figure 4: Dividing the world in a target country and the rest-of-the-world in the bi-regional model using USA and Canada as examples.

\section{Expert Views on the Future of Migration}

Future intensities and spatial patterns of international migration will be shaped by a myriad of forces, ranging from economic development to policy interaction to demographic trends. Such complexities render any approach to projecting global migration trajectories naturally difficult and lead to a large degree of uncertainty about future trends. Consequently, international projection-making agencies commonly use simplistic assumptions of net-migration converging to zero over the projection horizon, despite sustained increases in net migration in many developed countries.

The bi-regional projection model allows us to circumvent the aforementioned problems by making assumptions for immigration and emigration flows. We tackle the challenging task of making plausible assumptions about future international migration by drawing on expert views 
about the future trajectory of migration, which were collected using a structured online survey (referred to as source experts' views hereafter) and a two-day expert group meeting (referred to as meta-experts' views hereafter).

\subsection{Source Expert's Views from the Online Survey}

The online survey was sent to all members of international population associations in mid-2011. The survey's objective was to obtain source experts' views on the likely impact of various factors on future immigration and emigration levels to/ from a particular country of the respondent's choice. The impact that economic, demographic, environmental and policy factors may have on migration combine the various pull and push forces prevailing in more developed and less developed countries and were formulated as neutral arguments. For example, one argument on economic growth reads: "Remittances will become more important for the economic development of migrant-sending countries".

For each of the 30 arguments, the experts were asked:

- "Based on your understanding of current scientific knowledge and with reference to the period up to 2030, do you think the argument is... (very likely to be wrong to very likely to be right)"

- "If the above argument were completely true, what effect would this have on future levels of immigration? (strongly decreasing to strongly increasing)"

- "If the above argument were completely true, what effect would this have on future levels of emigration? (strongly decreasing to strongly increasing)"

Three key indicators are provided:

- Validity, ranging from 0 to 1 indicates whether a given argument is likely to be true, based on five predefined response options and the validity score attached to them.

- Impact, assessing the hypothetical influence of a given trend on migration. The predefined range was from -1 (strongly negative) to +1 (strongly positive).

- Net impact, assessing validity and impact in combination. This was calculated by multiplying the validity score with the impact score.

The respondents were also asked to give a point estimate for the number of net migrants they expect the country of their choice to gain or lose. Unfortunately, our new directional flow estimates were not yet finalised at the time when the survey was distributed. We thus relied on the UN estimates of net numbers of migrants as the only migration dataset available for the 
period 2005-10 that covered all countries in the world. The results from this section of the online survey were inconclusive; reflecting the dearth of migration theory that could provide guidance in determining future trajectories, and the fact that scientific endeavour into thinking about future international migration has lagged behind fertility and mortality. Moreover, respondents noted problems with setting the 80 percent range using the web interface, which may explain a large degree of disagreement among respondents about future net migration levels for individual countries. Given that the bi-regional projection model requires assumptions for immigration and emigration flows rather than net migration, we found the assessment of the impact of arguments more beneficial than the point estimates for setting migration assumptions. The 30 arguments pertaining to economic, demographic, climatic and policy impacts on migration were grouped into five clusters. Towards the end of the online survey, respondents were asked to assign weights of relative importance to each of these clusters. The weights sum to 100 percent for all clusters combined. We computed the mean cluster weights over all respondents and countries, as they showed only minor regional differences. Overall, we obtained 122 responses in the migration module of the online survey. Table 2 shows the distribution of the responses across regions for which responses were given. There was a reasonable spread across regions, with a considerable share of responses for North America and Europe.

Table 2: Online survey responses by region

\begin{tabular}{lr}
\hline Region & Responses \\
\hline North America & 29 \\
Latin America & 17 \\
Europe & 36 \\
Frm Soviet Union & 1 \\
West Asia & 5 \\
South Asia & 9 \\
East Asia & 3 \\
South-East Asia & 7 \\
Oceania & 6 \\
Africa & 9 \\
\hline Total & 122 \\
\hline
\end{tabular}

Figures 5 and 6 summarise source experts' views on the likely future trajectory of global migration flows over the period 2010 to 2030 . The figures indicate the relative weight of each of the five clusters and the mean net impact of each argument at region level. The relative weight of each cluster is indicated by the slice of the circle devoted to them. For example, the largest slice of the circle is devoted to the cluster of arguments on economic factors since this cluster was expected to have the strongest relative impact. Within each cluster, the arguments are arranged 
based on their ID (a full list of arguments is given in the Appendix). The net impact, calculated simply by multiplying the impact score with the validity score pertaining to each argument, is shown on a scale from -0.8 to 0.8 . Values below 0 (inside of the solid black line) cause the intensity of migration to decrease; and values above 0 (outside of the solid black line) cause migration to increase. To aid visual examination of the survey results, the argument ID and an abridged version of the argument text are shown on the outside of the circular graph.

Figure 5 depicts the net impact of each argument on future immigration, calculated as region-specific mean net impact. The effect that each argument is expected to have on immigration varies substantially across regions, reflecting the well-established pattern of sending and receiving countries. For example, argument M 1-7 "Economic recession" has a negative impact on immigration to North America and Europe, and a positive impact on immigration to Africa. The latter effect appears to be primarily driven by return movements of African migrants as a result of less demand for migrant workers in North America and Europe. The overall picture is one of more positive than negative effects of arguments on future immigration. Arguments pertaining to climate and migration costs are expected to increase migration levels, although the relative importance attributed to these two clusters is low, as indicated by the small slice of the circle. 


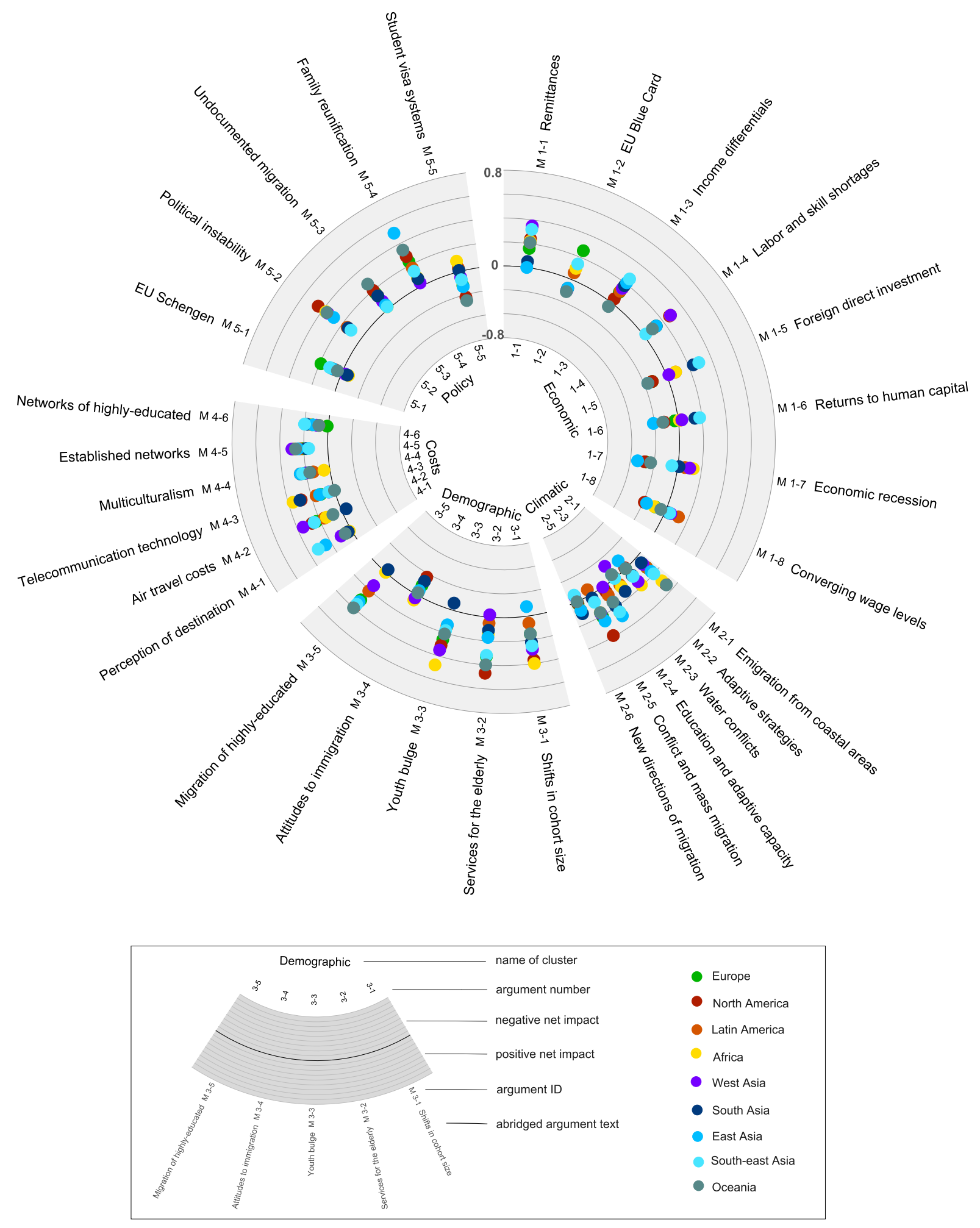

Figure 5: Expert views on the mean net impact of each argument on future immigration. Arguments within each cluster were arranged in circular layout. The size of the segments indicates the cluster's relative importance. The mean net impact of each argument is shown on a scale from -0.8 to +0.8 , with negative net impact scores causing immigration to decline and positive scores causing immigration to increase. The mean net impact is calculated by multiplying the impact score with the validity score pertaining to each argument. 
Arguments pertaining to economic forces are expected to have the strongest impact on immigration levels. Immigration is expected to increase if remittances become increasingly important for economic development in sending countries, if income differentials between countries further widen, and if population ageing results in increasing labour and skill shortages in more developed countries. At the other end of the spectrum, immigration to North America and Europe would decline if foreign direct investment in developing countries as a stimulus to economic growth rectifies the imbalance between supply and demand in the labor markets in those countries (M 1-5), or if global wage levels will converge in the long run (M 1-8). The strongest negative impact is given to economic recessions in industrialized countries and the resulting decline in demand for migrants (M 1-7).

The impact of each argument on future emigration (see Figure 6) reveals larger differences between regions than for immigration. The impacts are expected to be very strong for Africa (white circle) and East Asia (light grey triangle), whereas the expected impact on emigration from Europe and North America is closer to zero for most arguments. Noteworthy are the strong positive impacts of arguments on remittances (M 1-1), a demographic youth bulge (M 3-3), education differentials (M 3-5) and family reunification (M 5-4) on emigration.

In summary, it appears that overall trends in future migration will be driven mostly by economic and demographic developments, as well as selected policy-related factors. Environmental forces are expected to have a strong impact, but the validity scores of the arguments within this cluster were the lowest of all 30 arguments, and the relative weight of the cluster was the smallest of all clusters. These results partly reflect the large degree of uncertainty about potential negative impacts of climate change on migration, with most environmentally-induced migration expected to be within countries rather than across borders. 


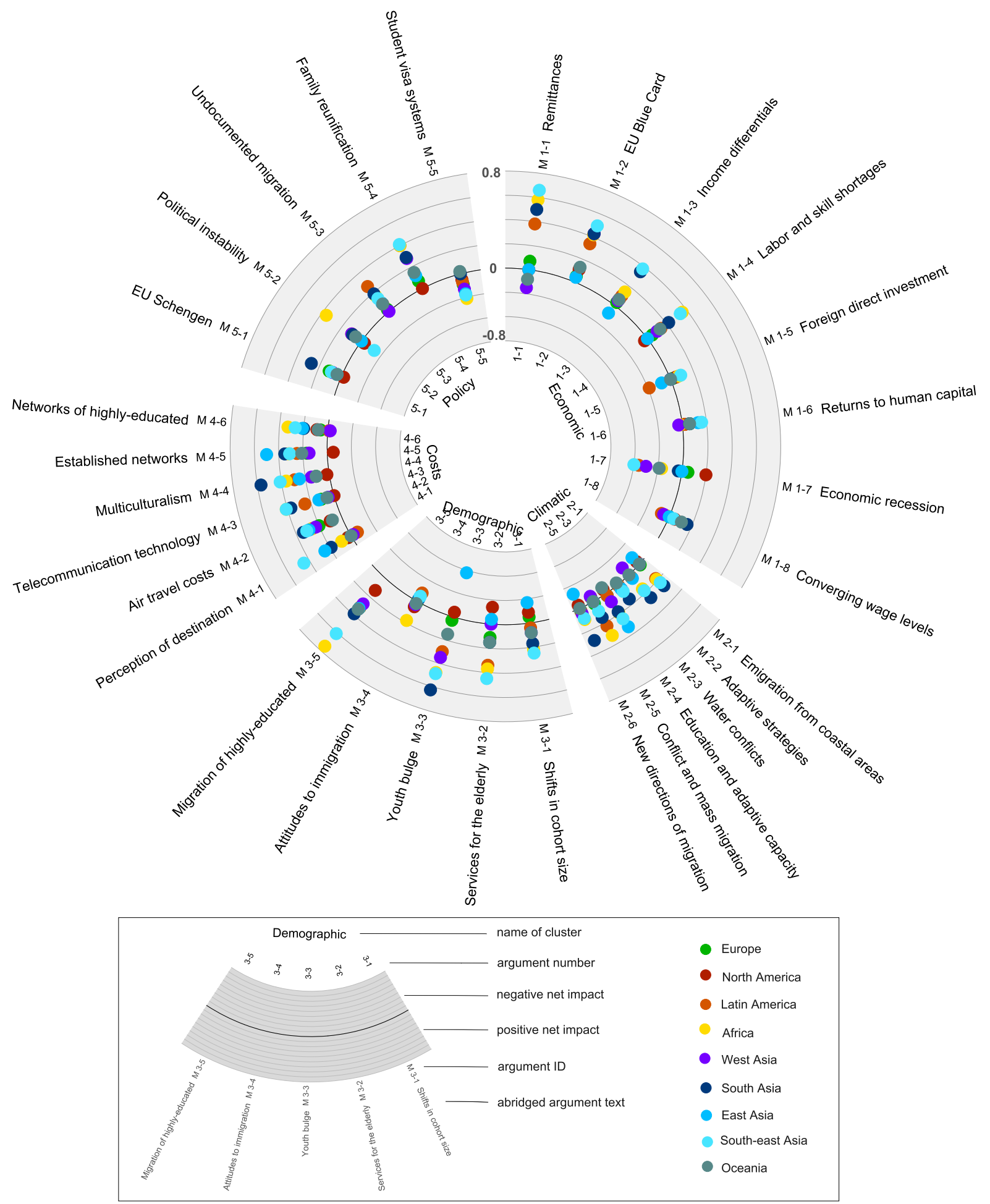

Figure 6: Expert views on the mean net impact of each argument on future emigration. Arguments within each cluster were arranged in circular layout. The size of the segments indicates the cluster's relative importance. The mean net impact of each argument is shown on a scale from -0.8 to +0.8 , with negative net impact scores causing emigration to decline and positive scores causing emigration to increase. The mean net impact is calculated by multiplying the impact score with the validity score pertaining to each argument. 


\subsection{Meta Expert's Views}

These results from the online survey were complemented by an expert group meeting held at the University of Colorado at Boulder, US in autumn 2011. The participants, representing different geographic regions, scientific disciplines and areas of expertise included nine meta-experts, one representative of the University of Colorado and three representatives of the Wittgenstein Centre. Selected results from the online survey were presented to the meeting participants to serve as a basis for discussion. All participants stressed the importance of departing from convergence to zero assumptions and making plausible assumptions about future migration flows. They also emphasized the need for more adequate data on contemporary migration flows. The lack of flow data and the dominance of zero convergence scenarios in existing global population projections meant that discussing future levels of immigration and emigration for each country in the world was too ambitious a task.

In considering the issues related to the dearth of existing migration projections that could have served as a basis for discussions about future numbers of migrants, the aim of the meeting was to elaborate in qualitative rather than quantitative terms the likely future trajectory of migration flows to and from the major regions. The meta-experts were asked to identify the arguments from the online survey that in their opinion best capture the key determinants of migration that are likely to be most influential in shaping future trends. The seven arguments identified by the participants are shown in Figures 7 and 8 and listed in Table 3. In several round table discussions, we then elaborated how these arguments will shape migration to and from major regions. Meta-experts expressed their views on whether arguments would increase, decrease or have no impact on immigration and emigration. Figures 7 and 8 depict the outcomes of the roundtable discussions and provide a comparison with the results of the online survey. 


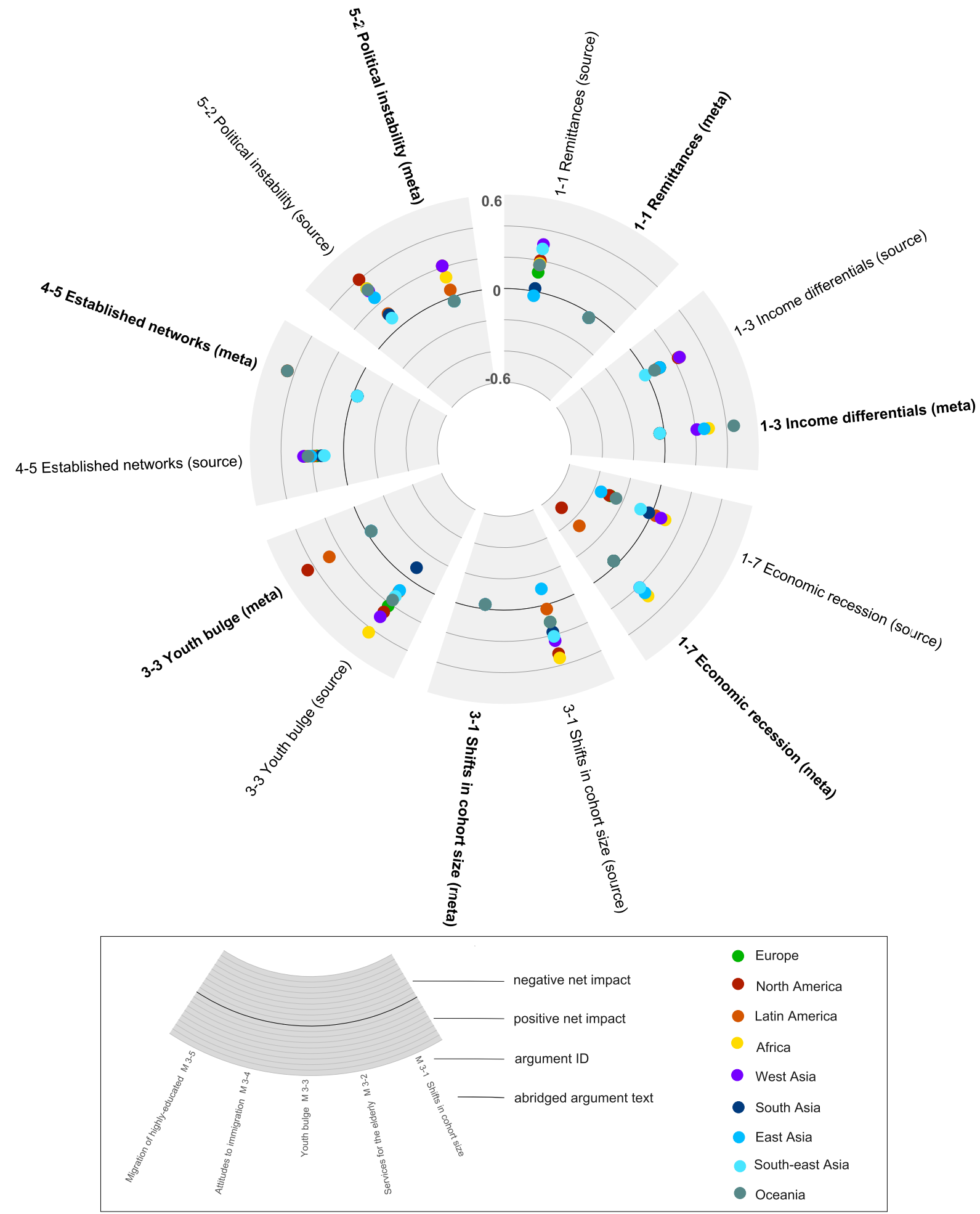

Figure 7: Expert views on future immigration among source experts (normal font) and meta expert (bold font) for seven arguments identified by meta experts as having a strong impact on future trends. Results for source experts are identical to those shown in Figure 10. Meta expert views for selected regions only. See Table 7 for the full argument texts corresponding to the abridged texts. 

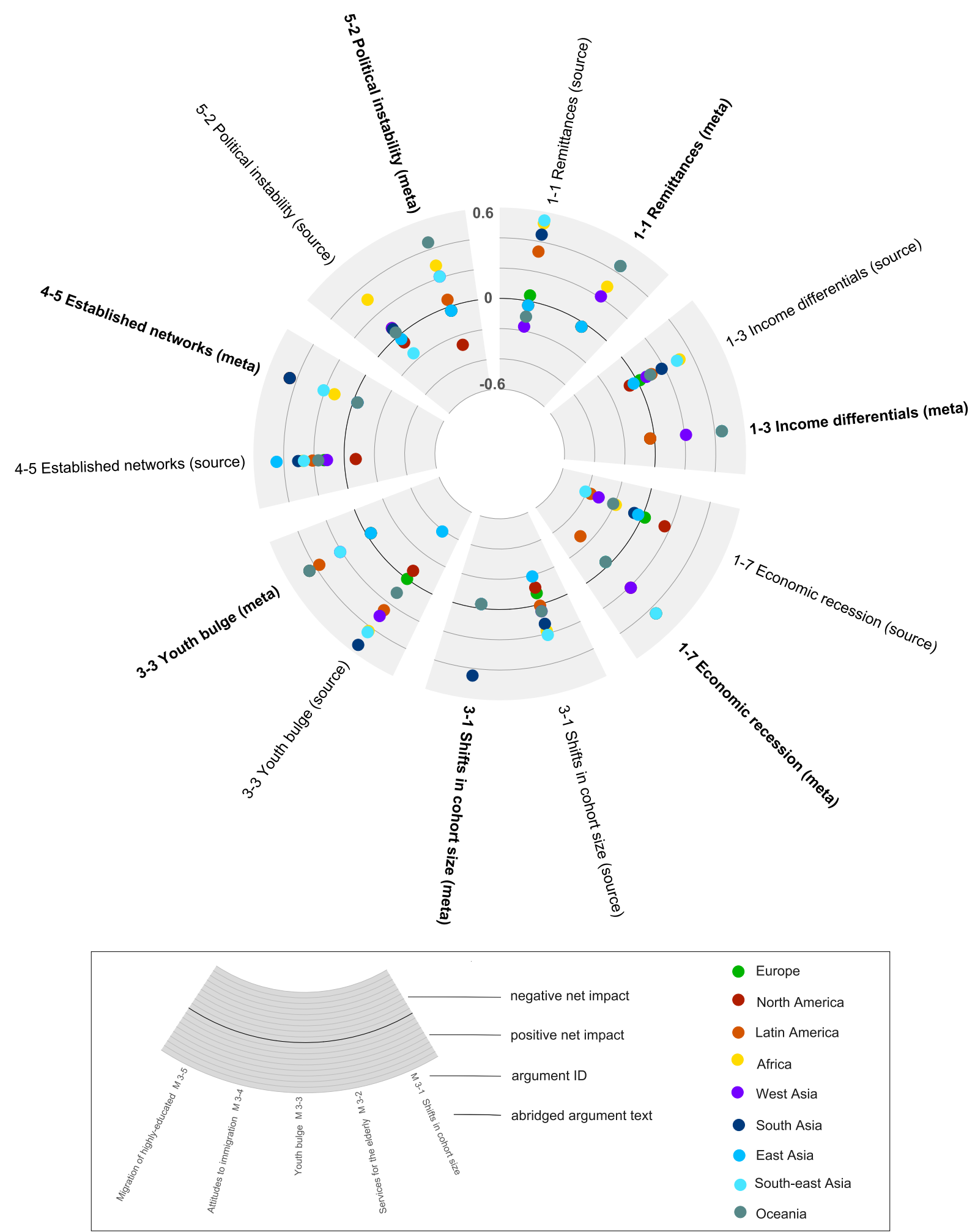

Figure 8: Expert views on future textitemigration among source experts (normal font) and meta expert (bold font) for seven arguments identified by meta experts as having a strong impact on future trends. Results for source experts are identical to those shown in Figure 11. Meta expert views for selected regions only. See Table 3 for the full argument texts corresponding to the abridged texts. 
The meta-experts were broadly in agreement about the way our seven key arguments are likely to shape future trends. The overall pattern of expert views suggests that prolonged economic recession in the traditional migrant-receiving countries in the developed world is the only argument that may cause immigration to the receiving countries and emigration from the traditional sending countries to decrease. All other arguments, especially those pertaining to cohort size and occurrence of a youth bulge are expected to lead to higher volumes of migration.

Table 3: Key arguments identified by meta experts as having a strong impact on future trends.

\begin{tabular}{ll}
\hline ID & Argument text \\
\hline 1-1 & Remittances will become more important for the economic development of migrant-sending countries. \\
1-4 & Temporary labour migration will increasingly compensate for skills shortages in developed countries \\
& and thus replace permanent migration. \\
1-7 & Major economic recessions/stagnation in industrialized countries will lead to less demand for migrants. \\
3-1 & Shifts in cohort size, especially related to the baby boom and bust, will play \\
& an important role in shaping international migration levels. \\
3-3 & The propensity to move abroad among 15 to 29 year olds will be particularly high in countries \\
& $\begin{array}{l}\text { with a large "youth bulge". } \\
\text { 4-5 }\end{array}$ \\
5-2 & Political instability and oppression in African and Middle Eastern countries will result in more \\
& people seeking political asylum in democratic countries.
\end{tabular}

\section{Specification and Justifications of Assumptions}

The development of assumptions for future immigration and emigration for each country in the world was primarily based on (a) meta experts suggesting a 'business as usual scenario' to be most appropriate as a medium scenario, (b) meta experts emphasising the importance of accounting for changes in the size and age structure of origin populations through assumptions for migration rates rather than numbers, and (c) the net impact scores for the seven key arguments identified by the meta experts.

The expert views collected in the online survey and subsequent discussions with metaexperts focussed on the period 2010 to 2060. Likely trends for the period 2060 to 2100 were not considered in the meeting because of major uncertainties concerning migration trends in the second half of the century. In light of this uncertainty, we assume a gradual convergence to zero net migration over the period 2060 to 2100 . This is achieved by converging each country's immigration and emigration flows towards their average, so that each country's net migration reaches zero in the last projection period, 2095-2100. 


\subsection{The Medium Scenario}

A 'business as usual' scenario assuming jump-off period rates to remain constant was suggested during the expert group meeting. A constant-rates scenario was therefore preferred over a time series forecast, the assumption of turning points, or a projection model based on other projected covariates.

Our medium scenario therefore assumes immigration and emigration rates estimated for the period 2005-10 to remain constant throughout the projection horizon until 2060. We make assumptions for rates rather than absolute numbers to take into account changes in the population size and age structure of origin populations. For example, using migration rates assumptions, we ensure that emigration from strongly ageing and weakly growing populations in Eastern Europe will decrease over the projected period. Adjustments are made to the constant rates assumption for 25 countries where rapid changes to migration trends occurred in the last decade (e.g. immigration to Spain), which are unlikely to persist until the year 2060 (Table 4). 
Table 4: Percentage change in assumed rates of immigration and emigration over the first two projection periods under the medium scenario for countries where the constant-rates assumption appears not to be plausible. For example, immigration into Australia is assumed to decrease by 20 per cent in the period 2010-15 to 2015-20.

\begin{tabular}{|l|l|l|}
\hline Country & immigration & emigration \\
\hline Australia & -0.2 & - \\
Austria & -0.2 & - \\
Bahrain & -0.65 & 0.2 \\
Burundi & -0.2 & - \\
Czech Republic & -0.2 & - \\
Greece & -0.2 & - \\
Iceland & -0.2 & - \\
Ireland & -0.2 & - \\
Italy & -0.65 & - \\
Kuwait & -0.2 & - \\
Liberia & -0.2 & - \\
Luxembourg & -0.2 & - \\
Macao & -0.2 & - \\
Micronesia & - & -0.2 \\
Norway & -0.2 & - \\
Qatar & -0.65 & 0.2 \\
Samoa & - & -0.2 \\
Singapore & -0.65 & - \\
Spain & -0.65 & - \\
Sweden & -0.2 & - \\
Switzerland & -0.2 & - \\
Tonga & - & -0.2 \\
United Arab Emirates & -0.65 & 0.2 \\
United Kingdom & -0.2 & - \\
Zimbabwe & - & -0.2 \\
\hline
\end{tabular}

\subsection{Two Alternative 'what-if' Scenarios}

We drew on expert views regarding the impact of a set of arguments for future migration patterns and intensities for developing alternative immigration and emigration assumptions. The net impacts of seven key arguments for migration identified by the meta-experts as being most relevant in shaping future trajectories were translated into two 'what-if' scenarios. The number of scenarios had to be limited to two so that the migration scenarios could be readily combined 
with the high and low scenarios for fertility and mortality. A key distinction between the two migration scenarios had to be that one results in lower levels of global migration flows, whereas the other results in higher global volumes. We therefore based the first scenario on the net impact scores of all key arguments that cause immigration to the traditional receiving countries and emigration from the traditional sending countries to decrease. The second scenario was based on the net impact scores of all key arguments that yield higher immigration to the receiving countries. The resulting scenarios can be summarised as follows.

The "Rise of the East" (referred to as RE scenario hereafter) scenario assumes economic stagnation in Europe and North America, resulting in restrictive migration policies. South and south-east Asia become increasingly attractive destinations, resulting in a shift in global migration patterns. Assumptions under this scenario are based on the mean net impact of argument 1-7 "Economic recession".

The "Intensifying Global Competition" scenario (referred to as IGC scenario hereafter) assumes dynamic economic growth and social development, resulting in growing competition among governments and the private sector for (skilled) labour and natural resources, as well as between the traditional activities of agriculture and mining and industry, residential development and recreational activities. Economic growth in the developing world contributes towards rising levels of global mobility, which is paralleled by liberal immigration policies in the more developed world. Assumptions under this scenario are based on the mean net impact of arguments 1-4 "Labour and skill shortages", 2-3 "Water conflicts", 3-3 "Youth bulge", 4-5 "Established networks" and 5-2 "Political instability".

The mean net impact scores were translated into a set of multipliers, which cause the global volume of flows to decrease under the RE scenario and to increase under the IGC scenario. The multipliers were region-specific and applied to all countries in a given region in the first two projection periods (2010-15 and 2015-20). After 2020, rates are then kept constant until 2055-60. Figures 9 and 10 show assumed region-specific changes in immigration and emigration between 2005-10 and 2015-20 under alternative scenarios. For most countries, migration intensities are assumed to stay constant under the medium scenario, with some exceptions in Europe, Oceania, South-East Asia and West Asia. 


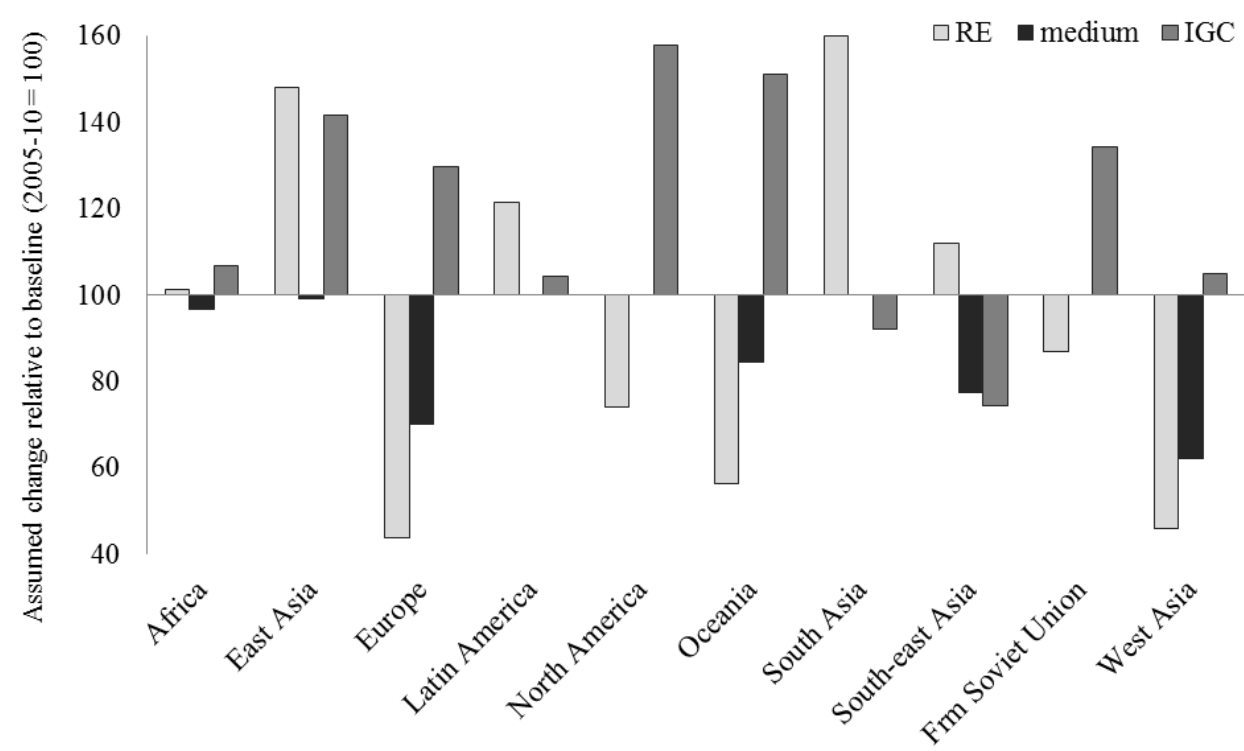

Figure 9: Translating expert views on future immigration into alternative scenarios: The assumed relative change in immigration volumes by region under the RE, medium and IGC scenarios. Immigration volumes in the jump-off period 2005-10 are set to 100 .

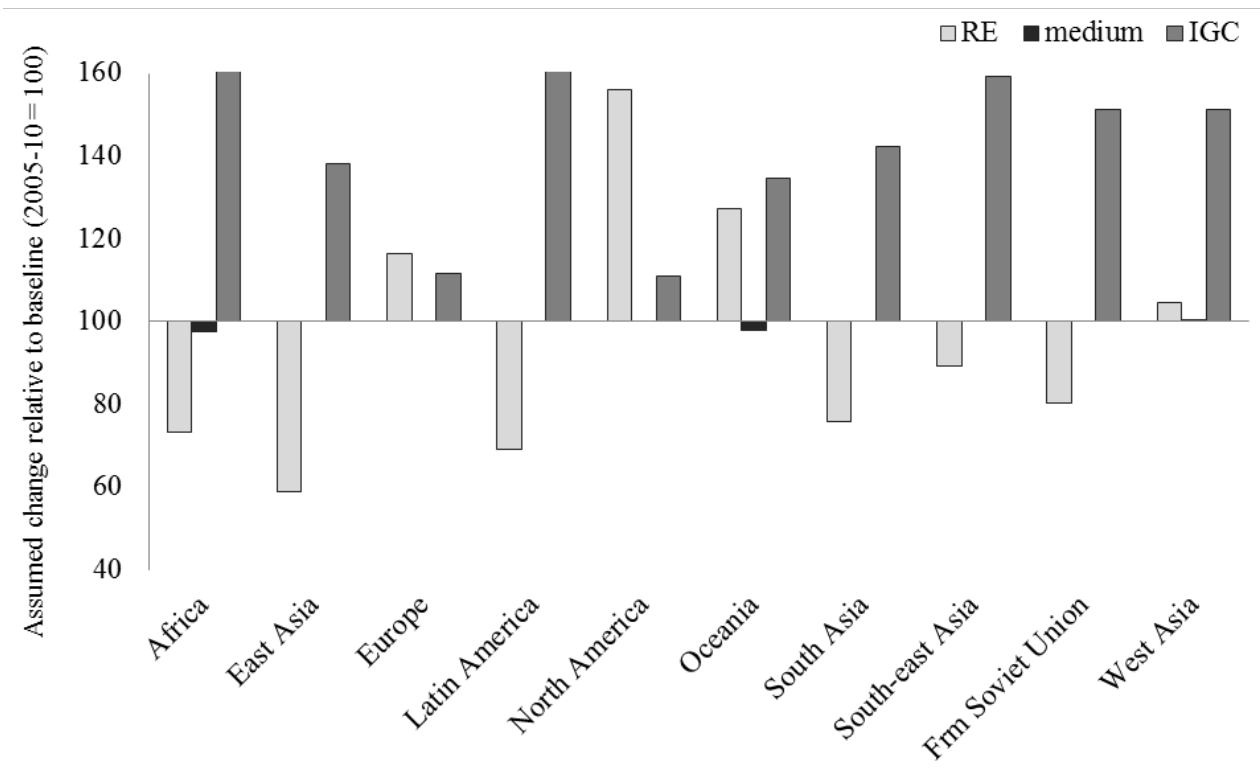

Figure 10: Translating expert views on future emigration into alternative scenarios: The assumed relative change in emigration volumes by region under the RE, medium and IGC scenarios. Emigration volumes in the jump-off period 2005-10 are set to 100.

The traditional receiving countries in Europe, North America and Oceania are assumed to record lower immigration volumes under the RE scenario and higher volumes under the IGC scenario. At the other end of the spectrum, East Asia, South Asia and South-East Asia 
are assumed to experience higher levels of immigration under the RE scenario. In East Asia, immigration volumes are assumed to rise under both the RE and the IGC scenarios, reflecting the sustained pattern of strong economic growth and hence the growing attractiveness of the region as a migrant destination.

To illustrate how expert opinion was translated into immigration and emigration assumptions for each of the 195 countries in the age-sex projections, Figure 11 shows the assumptions on future immigration for Austria.

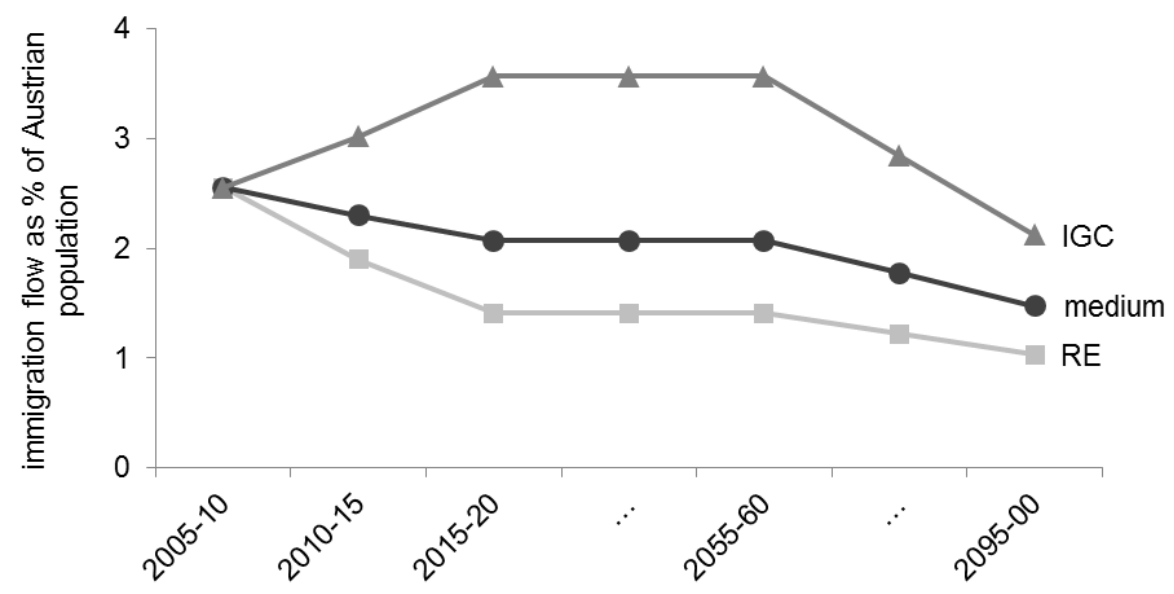

Figure 11: Assumed rates of immigration for Austria under alternative scenarios. Expert-based multipliers cause the estimated intensity of immigration in 2005-10 to decline under the RE scenario and to increase under the IGC scenario until 2015-20. Under the medium scenario, the estimated intensity in 2005-10 is assumed to decline slightly over the first two projected periods. All rates are assumed to remain constant over the period 2020 to 2060 . A gradual convergence to zero net migration is assumed for the period 2060 to 2100 .

\section{Projected Numbers of Migrants}

This section presents selected results of the bi-regional cohort-component population projections by age and sex for 195 countries. We focus on the projected numbers of migrants at world, region and country levels. A detailed discussion of the overall results of the population projections for 195 countries and the human capital projections for 171 countries are provided in Lutz et al. (forthcoming).

Figure 12 shows the projected number of global migrants under three alternative scenarios. In the five-year period 2005-10, an estimated 40 million people changed their country of residence. Under the medium scenario, this number is projected to decline to 32 million in 2015-20, due to the correction factors we applied under the medium scenario for the periods 2010-2015 and 2015-2020 to lower assumed volumes of immigration in selected countries. Be- 
cause we draw on a bi-regional flow model to project migration, our assumption of decreasing immigration flows to countries like Spain and Singapore over the first two projected periods results in fewer emigration from the origin countries (eg Latin America for Spain and Malaysia for Singapore) and thus smaller numbers of global migrants. Under the IGC scenario, global migration volumes are projected to increase substantially compared to the medium scenario, whereas the decline under the RE scenario is more subtle. The decline in global migration under the RE scenario is small because of the assumed shift in spatial patterns of global migration. Destinations in Europe and North America become less attractive, whereas destinations in Asia become increasingly popular.

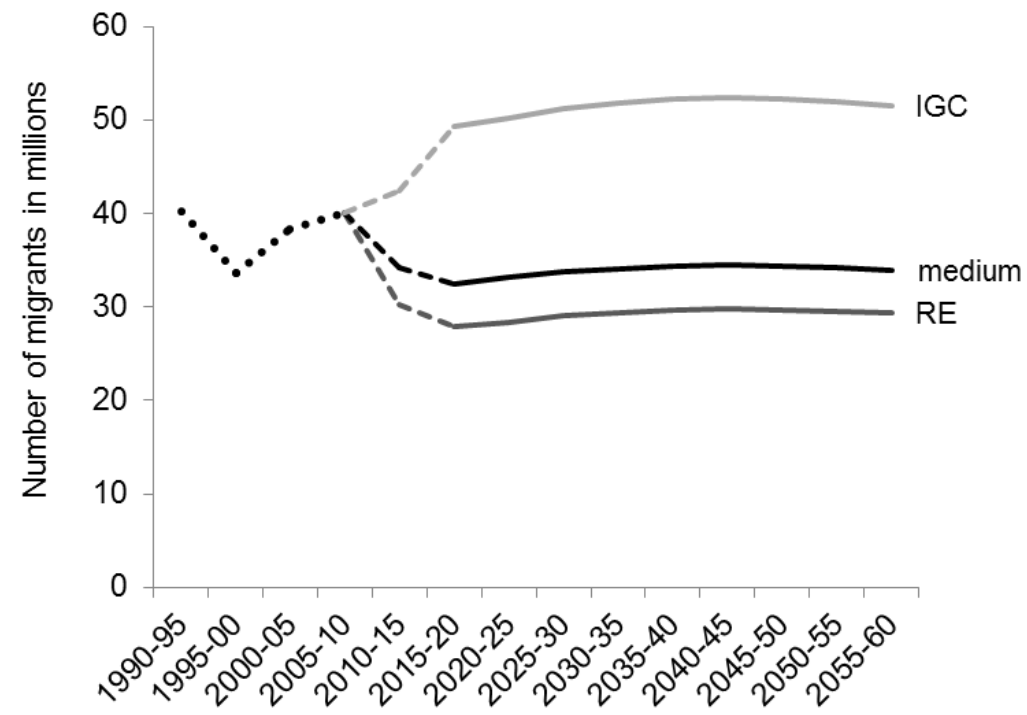

Figure 12: Estimated (1990-95 to 2005-10) and projected (2010-15 to 2055-60) number of global migrants moving over five-year periods under alternative scenarios.

Under all three scenarios, the global number of migrants is projected to peak in the period 2040-45, with population ageing combined with our assumed Rogers-Castro migration schedule causing numbers to decline thereafter. The dawning of an era of mass migration seems to be rather unlikely if current trends continue as assumed under the medium scenario.

Figures 13 to 15 depict the projected numbers of immigrants, emigrants and resulting net migration by region under alternative scenarios. Differences between scenarios are most pronounced in the traditional destination regions in North America, West Asia and Europe (for immigration) and the sending regions in South Asia and Africa (for emigration). Under the medium scenario, Sub-Saharan population growth is projected to boost emigration numbers, although at lower rates than commonly assumed. Population ageing in many parts of the world, including East Asia, Latin America and Europe, is projected to result in lower volumes of emigration from these ageing regions. 


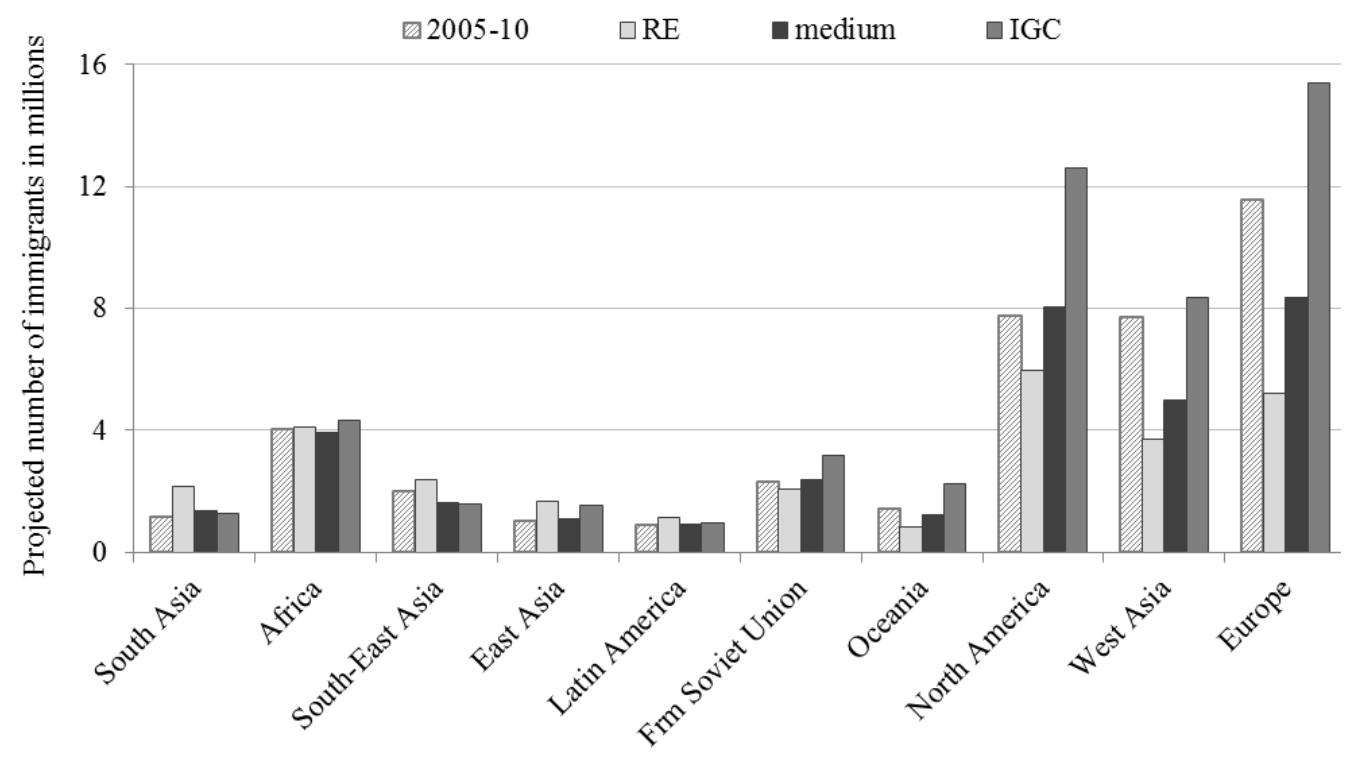

Figure 13: Estimated (2005-10) and projected (2055-60) number of immigrants moving over five-year periods under alternative scenarios, by region.

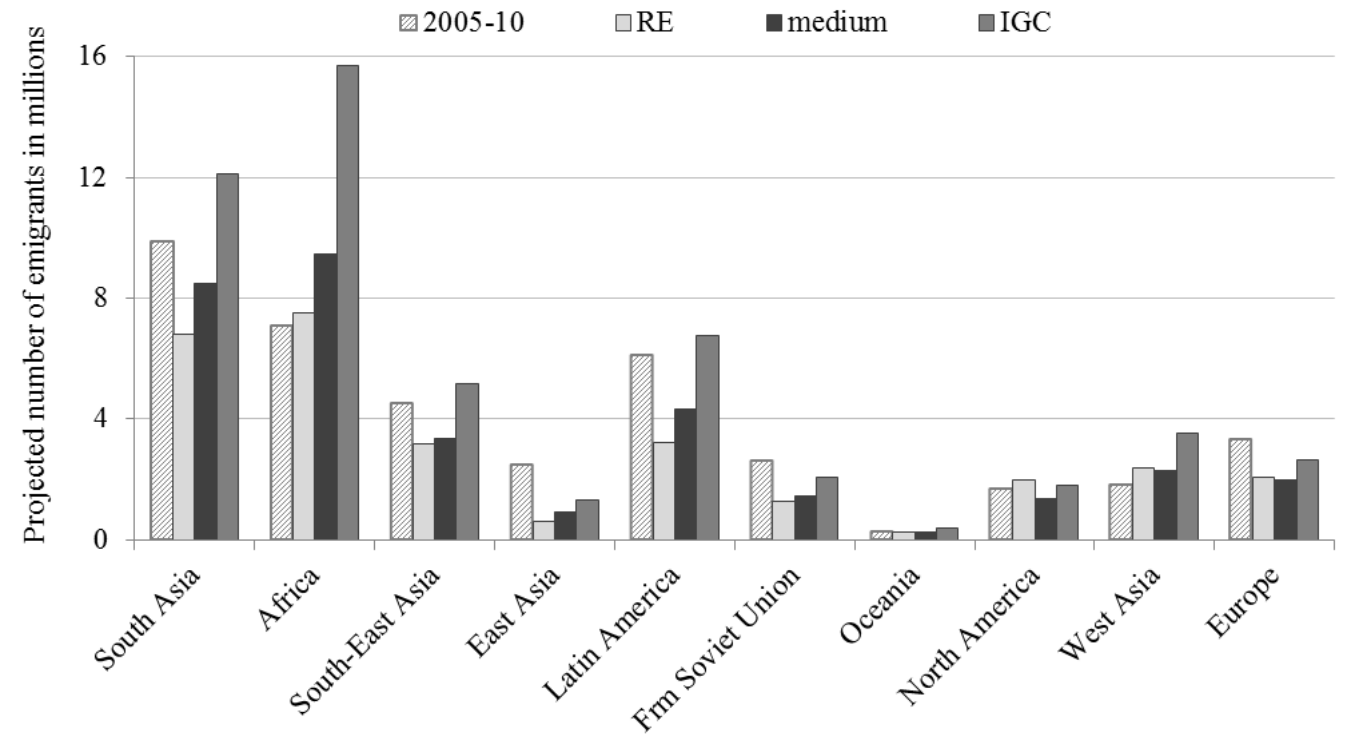

Figure 14: Estimated (2005-10) and projected (2055-60) number of emigrants moving over five-year periods under alternative scenarios, by region. 


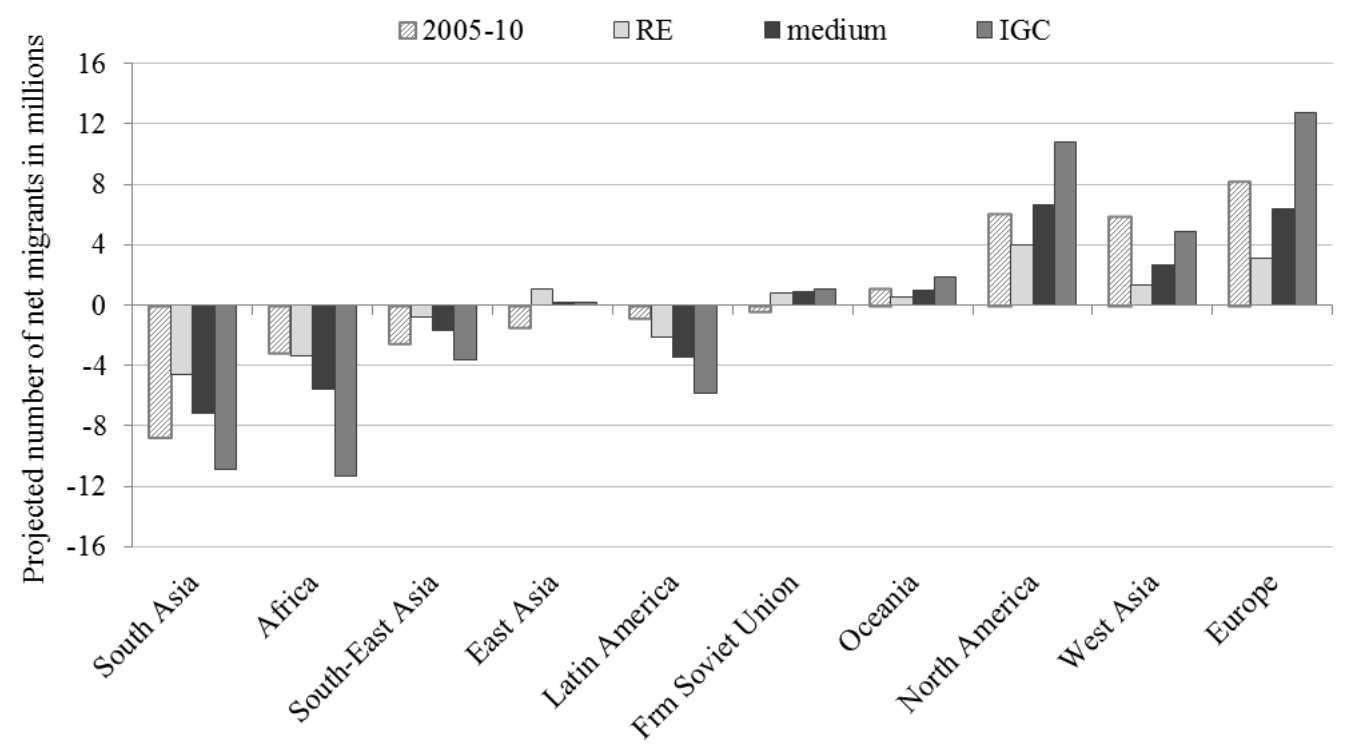

Figure 15: Estimated (2005-10) and projected (2055-60) number of net migrants under alternative scenarios, by region.

The overall pattern is one of projected increases in emigration from South Asia and Africa, much reduced losses in East Asia, smaller gains in West Asia and stable gains in North America and Europe. Since in the bi-regional model, immigration is projected as the product of the assumed immigration rate and population in the rest of the world, one could have expected a substantial increase in immigration numbers to North America and Europe as a result of global population growth. Figure 14 shows that the positive effect of population growth in the less developed world will be offset by widespread population ageing, which under the assumption of a Rogers-Castro migration schedule results in lower numbers of projected migrants.

Figure 16 shows the projected numbers of migrants for Austria until 2060. The results can be readily compared to the assumed immigration rates shown in Figure 11. 

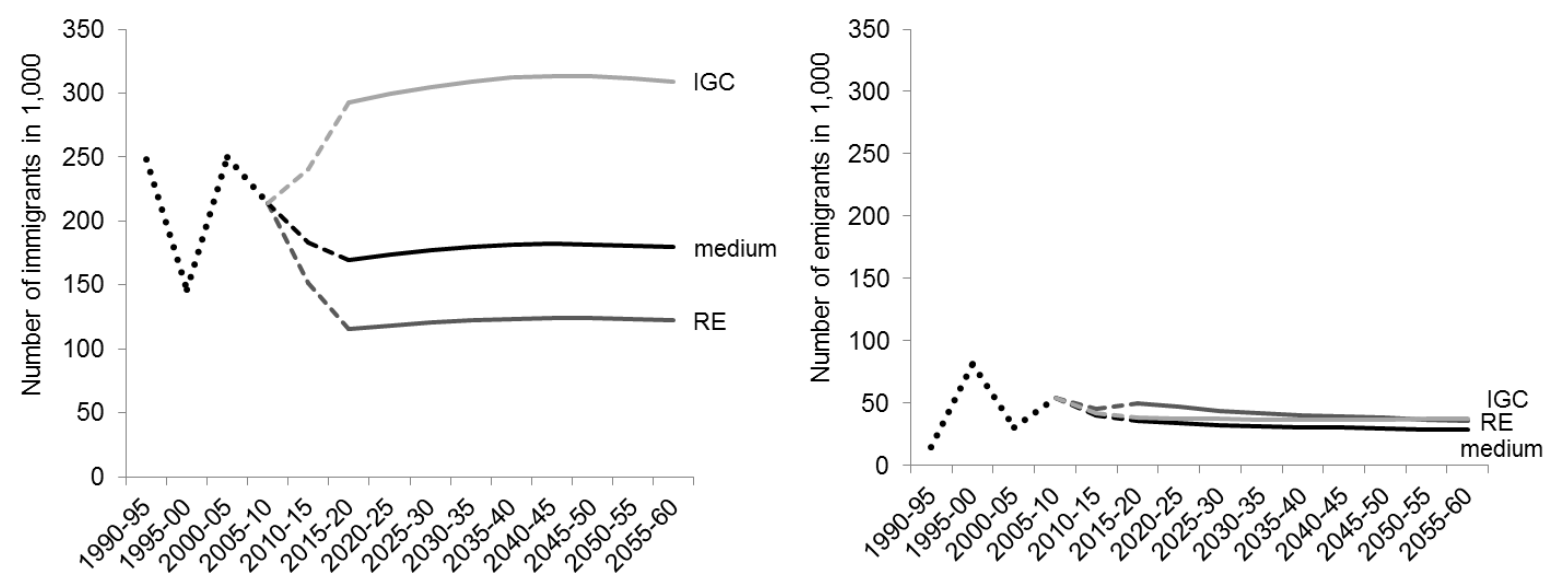

Figure 16: Estimated (1990-95 to 2005-10) and projected (2010-15 to 2055-60) numbers of immigrants and emigrants under alternative scenarios, Austria.

Using a projection model based on rates rather than numbers highlights the effects that changes in population size and age structure have on migrant numbers. The results for Austria demonstrate that Sub-Saharan population growth has no visible effect on projected numbers of immigrants. In contrast, population ageing is projected to result in a decline in emigrant numbers over the projection horizon.

Figures 17 and 18 compare the effects of the constant rates assumption for two countries with very different future population growth trajectories. Results are shown for five-year periods until 2060, after which a convergence to zero net migration is assumed. Bulgaria is predicted to experience rapid population ageing and an overall decline of its population, whereas Nigeria's young population is projected to grow strongly. The predicted number of emigrants is predicted to decline substantially in Bulgaria, whereas emigration from Nigeria is set to increase. Immigration to both countries is projected to be almost stable over the projection horizon. 

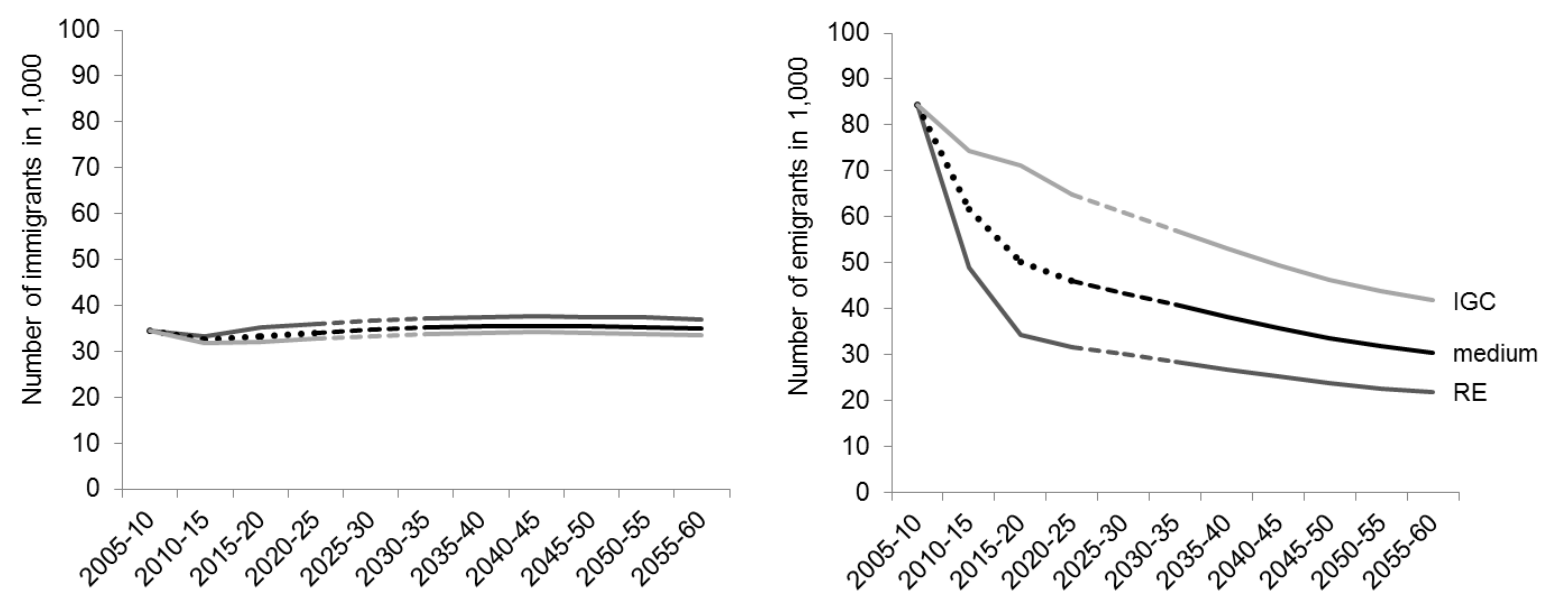

Figure 17: Estimated (2005-10) and projected (2010-15 to 2055-60) numbers of immigrants and emigrants under alternative scenarios, Bulgaria.
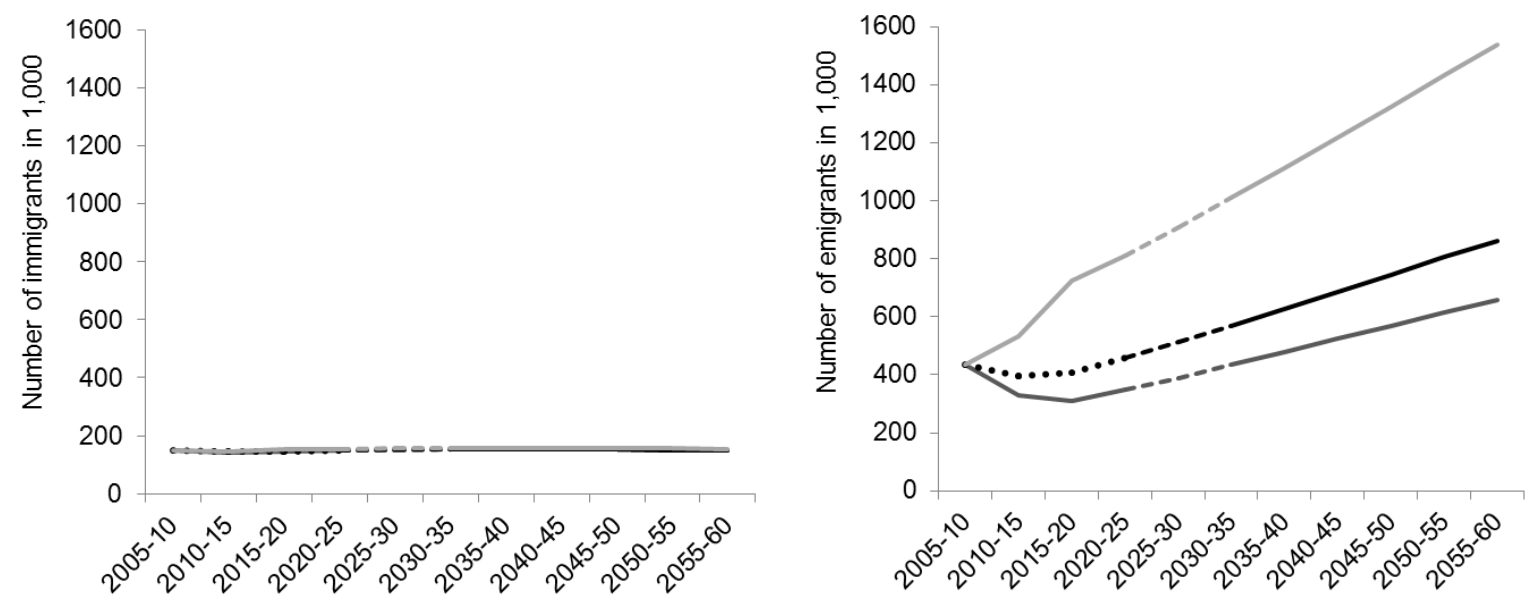

Figure 18: Estimated (2005-10) and projected (2010-15 to 2055-60) numbers of immigrants and emigrants under alternative scenarios, Nigeria.

\section{Summary}

International migration has increasingly become, and is likely to remain, a crucial component of the population dynamics of many sending and receiving nations. This paper presented a comprehensive overview of the economic, climate, political, policy and socio-demographic forces that affect migration. We could overcome the lack of comparable statistics that has thus far hindered the application of multi-region flow models at the global scale. Contemporary trends in global bilateral migration flows based on our new estimates point to stable intensities of the global flow of people since the mid-1990s. 
We circumvented the difficulties associated with making ad-hoc assumptions about future migration by drawing on expert judgement. The online survey revealed a strong agreement among experts about the factors most likely to shape future migration. Based on the respondents' collective judgement, we are more likely to see an increase in global migration levels than a decrease, unless current economic problems remain unsolved. Assuming a continuation of current trends as the most likely outcome and translating expert views into two alternative what-if scenarios allowed us to explore likely future migration trends.

The results of our population projections suggest that the global number of migrants will start declining in about 30 years. This is mostly because in the bi-regional flow model, slowed population growth and substantial population ageing result in fewer emigrants if a constant age schedule is assumed. The results also point to strong effects of population decline and ageing on projected emigration flows in many European countries, and they highlight differences in the future level and distribution of populations around the globe between the constant-rates and two 'what-if' scenarios. Using a medium scenario based on rates rather than numbers emphasizes the effects that changes in population size and age structure tend to have on emigration numbers. 


\section{References}

Abadan-Unat, N., 1995. Turkish migration to Europe. The Cambridge survey of world migration 279-284.

Abel, G.J., 2013a. Estimating global migration flow tables using place of birth data. Demographic Research 28, 505-546.

Abel, G.J., 2013b. migest: Useful R code for the Estimation of Migration. Retrieved 25 April, 2013, from http://cran.r-project.org/web/packages/migest/.

Abel, G.J., Sander, N., forthcoming. Quantifying global international migration flows. Manuscript in journal review.

Aide, T.M., Grau, H.R., 2004. Ecology. Globalization, migration, and Latin American ecosystems. Science 305, 1915-1916.

Angelucci, M., 2012. US Border Enforcement and the Net Flow of Mexican Illegal Migration.

Economic Development and Cultural Change 60, 311 - 357.

Bardsley, D.K., Hugo, G.J., 2010. Migration and climate change: examining thresholds of change to guide effective adaptation decision-making. Popul Environ 32, 238-262.

Beer, J. de, Raymer, J., Erf, R. van der, Wissen, L. van, 2010. Overcoming the Problems of Inconsistent International Migration data: A New Method Applied to Flows in Europe. European Journal of Population / Revue européenne de Démographie 26, 459-481.

Bilsborrow, R.E., 1997. International Migration Statistics: Guidelines for Improving Data Collection Systems. International Labour Organization.

Black, R., Kniveton, D., Schmidt-Verkerk, K., 2011. Migration and climate change: towards an integrated assessment of sensitivity. Environment and Planning A 43, 431-450.

Bloom, D.E., Canning, D., 2008. Global demographic change: dimensions and economic significance. Population and Development Review 34, 17-51.

Calavita, K., 1992. Inside the state: The Bracero Program, immigration, and the INS. Routledge New York.

Cardoso, L.A., 1980. Mexican emigration to the United States, 1897-1931: Socio-economic patterns. University of Arizona Press Tucson.

Cavalli-Sforza, L.L.L., Menozzi, P., Piazza, A., 1994. History And Geography Of Human Genes. Princeton University Press.

Cerrutti, M., Massey, D.S., 2001. On the auspices of female migration from Mexico to the United States. Demography 38, 187-200.

Christian Aid, 2007. Human tide: the real migration crisis. London: Christian Aid 14.

Clark, P.F., Stewart, J.B., Clark, D.A., 2006. The globalization of the labour market for health-care professionals. International Labour Review 145, 37-64.

Clark, X., Hatton, T.J., Williamson, J.G., 2004. What Explains Emigration Out of Latin America?

World Development 32, 1871-1890.

Coale, A.J., Banister, J., 1994. Five decades of missing females in China. Demography 31, 459-479.

Coleman, D.A., 1993. Contrasting Age Structures of Western Europe and of Eastern Europe and the 
Former Soviet Union: Demographic Curiosity or Labor Resource? Population and Development Review 19, 523-555.

Coleman, D.A., 2002. Replacement migration, or why everyone is going to have to live in Korea: a fable for our times from the United Nations. Phil. Trans. R. Soc. Lond. B 357, 583-598.

Cornelius, W.A., Salehyan, I., 2007. Does border enforcement deter unauthorized immigration? The case of Mexican migration to the United States of America. Regulation \& Governance 1, 139-153.

Coutin, S.B., 2003. Legalizing moves: Salvadoran immigrants' struggle for US residency. University of Michigan Press.

Crisp, J., 2000. Managing forced migration: evolving international responses to the refugee problem, in: Conference on International Migration and Foreign Policy.

Czaika, M., de Haas, H., 2011. The Effectiveness of Immigration Policies: A Conceptual Review of Empirical Evidence. IMI/DEMIG working paper, International Migration Institute, University of Oxford.

Davin, D., 2007. Marriage Migration in China and East Asia. Journal of Contemporary China 16, 83-95.

De Haas, H., 2011. The determinants of international migration: Conceptualizing policy, origin and destination effects. Oxford: International Migration Institute, IMI Working Paper.

De Haas, H., Vezzoli, S., 2011. Leaving Matters: The Nature, Evolution and Effects of Emigration Policies. IMI Working Paper 34 (DEMIG Project Paper 4), University of Oxford: International Migration Institute.

Deane, G., Gutmann, M.P., 2003. Blowin'down the road: Investigating bilateral causality between dust storms and population in the Great Plains. Population Research and Policy Review 22, 297-331.

Department of Immigration and Citizenship, 2011. Immigration Update, 2010-11. Canberra.

Duany, J., 2011. Blurred Borders: Transnational Migration between the Hispanic Caribbean and the United States. Univ of North Carolina Press.

Ediev, D., Coleman, D.A., Scherbov, S., 2007. Migration as a factor of population reproduction. Vienna Inst. of Demography.

Ellermann, A., 2006. Street-level democracy: How immigration bureaucrats manage public opposition. West European Politics 29, 293-309.

Espenshade, T.J., 2001. Replacement Migration from the Perspective of Equilibrium Stationary Populations. Population and Environment 22, 383-389.

Fassmann, H., Munz, R., 1992. Patterns and Trends of International Migration in Western Europe. Population and Development Review 18, 457-480.

Fitzgerald, D., 2009. A nation of emigrants: How Mexico manages its migration. University of California Pr.

Gibney, M.J., 2004. The Ethics and Politics of Asylum: Liberal Democracy and the Response to Refugees. Cambridge University Press.

Gindling, T.H., 2009. South-South Migration: The Impact of Nicaraguan Immigrants on Earnings, Inequality and Poverty in Costa Rica. World Development 37, 116-126.

Grasmuck, S., 1982. Migration within the Periphery: Haitian Labor in the Dominican Sugar and Coffee 
Industries. International Migration Review 16, 365-377.

Grasmuck, S., Pessar, P.R., 1991. Between Two Islands: Dominican International Migration. University of California Press.

Gray, C., 2009. Environment, Land, and Rural Out-migration in the Southern Ecuadorian Andes. World Development 37, 457-468.

Gray, C., Mueller, V., 2012. Drought and Population Mobility in Rural Ethiopia. World Development 40, 134-145.

Green, A.G., Green, D.A., 1995. Canadian Immigration Policy: The Effectiveness of the Point System and Other Instruments. The Canadian Journal of Economics / Revue canadienne d'Economique 28, 1006-1041.

Grosfoguel, R., 1997. Colonial Caribbean migrations to France, The Netherlands, Great Britain and the United States. Ethnic and Racial Studies 20, 594-612.

Guilmoto, C.Z., 2007. Sex-ratio imbalance in Asia: Trends, consequences and policy responses. Paris: LPED/IRD.

Gutmann, M.P., Parton, W.J., Cunfer, G., Burke, I.C., 2005. Population and environment in the US Great Plains. National Research Council Population, land use, and environment. National Academies Press, Washington, DC 84-105.

Haddad, E., 2003. The Refugee: The Individual between Sovereigns. Global Society 17, 297-322. Hanson, G.H., McIntosh, C., 2010. The Great Mexican Emigration. Review of Economics and Statistics 92, 798-810.

Hatton, T.J., 2004. Seeking asylum in Europe. Economic Policy 19, 5-62.

Held, D., 1995. Democracy and the Global Order: From the Modern State to Cosmopolitan Governance. Stanford University Press.

Henning, S., Hovy, B., 2011. Data Sets on International Migration. International Migration Review 45, 980-985.

Henry, S., Schoumaker, B., Beauchemin, C., 2003. The Impact of Rainfall on the First Out-Migration: A Multi-level Event-History Analysis in Burkina Faso. Population and Environment 25, 423-460.

Holzer, T., Schneider, G., Widmer, T., 2000. The Impact of Legislative Deterrence Measures on the Number of Asylum Applications in Switzerland (1986-1995). International Migration Review 34, 1182-1216.

Hugo, G.J., 1996. Environmental Concerns and International Migration. International Migration Review 30, 105-131.

Hunter, L.M., 2005. Migration and Environmental Hazards. Popul Environ 26, 273-302.

Hunter, L.M., Murray, S., Riosmena, F., forthcoming. Climatic Variability and U.S. Migration from Rural Mexican Livelihoods. International Migration Review.

International Displacement Monitoring Centre (IDMC), 2013. Global Overview 2012: People internally displaced by conflict and violence.

Kandel, W., Massey, D.S., 2002. The Culture of Mexican Migration: A Theoretical and Empirical Analysis. Social Forces 80, 981-1004.

Keyfitz, N., 1971. Migration as a means of population control. Population Studies 25, 63-72. 
King, R., Skeldon, R., 2010. "Mind the Gap!” Integrating Approaches to Internal and International Migration. Journal of Ethnic and Migration Studies 36, 1619-1646.

Krissman, F., 2000. Immigrant labor recruitment: US agribusiness and undocumented migration from Mexico. Immigration research for a new century: Multidisciplinary perspectives 277-300.

Krzywinski, M., Schein, J., Birol, İ., Connors, J., Gascoyne, R., Horsman, D., Jones, S.J., Marra, M.A., 2009. Circos: An information aesthetic for comparative genomics. Genome Res. 19, 1639-1645.

Kupiszewska, D., Nowok, B., 2008. Comparability of Statistics On International Migration flows In The European Union, in: Willekens, F., Raymer, J. (Eds.), International Migration in Europe: Data, Models and Estimates. Wiley, London, England, pp. 41-73.

Kureková, L., 2011. From job search to skill search: political economy of labour migration in Central and Eastern Europe (PhD thesis). Department of International Relations and European Studies, Central European University, Budapest.

Laczko, F., Collett, E., 2005. Assessing the tsunami's effects on migration. Geneva: International Organization for Migration.

Lang, H.J., 2002. Fear and Sanctuary: Burmese Refugees in Thailand. SEAP Publications.

Lee, E., 2003. At America's Gates: Chinese Immigration During the Exclusion Era, 1882-1943. Univ of North Carolina Press.

Levitt, P., 1998. Social Remittances: Migration Driven Local-Level Forms of Cultural Diffusion. International Migration Review 32, 926.

Levitt, P., Lamba-Nieves, D., 2011. Social Remittances Revisited. Journal of Ethnic and Migration Studies 37, 1-22.

Lindstrom, D.P., Ramírez, A.L., 2010. Pioneers and Followers: Migrant Selectivity and the

Development of U.S. Migration Streams in Latin America. The ANNALS of the American Academy of Political and Social Science 630, 53-77.

Ling, L.H.-M., 1984. East Asian Migration to the Middle East Causes, Consequences and Considerations. International Migration Review 18, 19-36.

Lundquist, J.H., Massey, D.S., 2005. Politics or Economics? International Migration during the Nicaraguan Contra War. Journal of Latin American Studies 37, 29-53.

Lutz, W., Butz, W. and K.C., S. (eds), forthcoming. World Population and Human Capital in the 21st Century, Oxford University Press.

Massey, D.S., 1990. Social Structure, Household Strategies, and the Cumulative Causation of Migration. Population Index 56, 3.

Massey, D.S., Arango, J., Hugo, G.J., Kouaouci, A., Pellegrino, A., Taylor, J.E., 1993. Theories of International Migration: A Review and Appraisal. Population and Development Review 19, 431-466. Massey, D.S., Arango, J., Hugo, G.J., Kouaouci, A., Pellegrino, A., Taylor, J.E., 1998. Worlds in motion: Understanding international migration at the end of the millennium. Oxford University Press, USA.

Massey, D.S., Aysa-Lastra, M., 2011. Social capital and international migration from Latin America. International journal of population research 2011.

Massey, D.S., Goldring, L., Durand, J., 1994. Continuities in Transnational Migration: An Analysis of 
Nineteen Mexican Communities. American Journal of Sociology 99, 1492-1533.

Massey, D.S., Sana, M., 2003. Patterns of U.S. Migration from Mexico, the Caribbean, and Central America. Migraciones Internacionales 2, 5-39.

Mayda, A.M., 2010. International migration: a panel data analysis of the determinants of bilateral flows. Journal of population economics 23, 1249-1274.

Mayer, T., Zignago, S., 2012. Notes on CEPII's Distances Measures: The GeoDist Database. SSRN. McDonald, D.A., 2000. On borders: Perspectives on international migration in Southern Africa.

Palgrave MacMillan.

McDonald, P., Temple, J., 2008. Demographic and labour supply futures for Australia. Report for the Department of Immigration and Citizenship. Available from: www. immi. gov. au.

McLeman, R., 2011. Settlement abandonment in the context of global environmental change. Global Environmental Change 21, Supplement 1, S108-S120.

McLeman, R., Hunter, L.M., 2010. Migration in the context of vulnerability and adaptation to climate change: insights from analogues. Wiley Interdisciplinary Reviews: Climate Change 1, 450-461.

McLeman, R., Smit, B., 2006. Migration as an adaptation to climate change. Climatic Change 76, 31-53.

Meze-Hausken, E., 2000. Migration caused by climate change: how vulnerable are people inn dryland areas? Mitigation and Adaptation Strategies for Global Change 5, 379-406.

Mitchell, C., 1989. International Migration, International Relations and Foreign Policy. International Migration Review 23, 681.

Myers, N., 2002. Environmental refugees: a growing phenomenon of the 21st century. Phil. Trans. R. Soc. Lond. B 357, 609-613.

Nawrotzki, R., Hunter, L.M., Dickinson, T.W., 2012. Natural resources and rural livelihoods.

Demographic Research 26, 661-700.

Office of Immigration Statistics, 2010. 2009 Yearbook of Immigration Statistics. U.S. Department of Homeland Security, Washington, D.C.

Ortega, F., Peri, G., 2009. The Causes and Effects of International Migrations: Evidence from OECD Countries 1980-2005 (Working Paper No. 14833). National Bureau of Economic Research.

Özden, C., Parsons, C.R., Schiff, M., Walmsley, T.L., 2011. Where on Earth is Everybody? The Evolution of Global Bilateral Migration 1960-2000. The World Bank Economic Review 25, 12-56.

Pachauri, R.K., Reisinger, A., 2007. IPCC fourth assessment report. IPCC Fourth Assessment Report. Paldam, M., 2003. Economic freedom and the success of the Asian tigers: an essay on controversy. European Journal of Political Economy 19, 453-477.

Parrado, E.A., Cerrutti, M., 2003. Labor Migration between Developing Countries: The Case of Paraguay and Argentina1. International Migration Review 37, 101-132.

Passel, J.S., Cohn, D., Center, P.H., 2009. Mexican Immigrants: How Many Come? How Many Leave? Pew Hispanic Center Washington.

Piore, M.J., 1980. Birds of Passage: Migrant Labor and Industrial Societies, New Ed. ed. Cambridge University Press, Cambridge, United Kingdom.

Preston, S.H., Himes, C., Eggers, M., 1989. Demographic Conditions Responsible for Population 
Aging. Demography 26, 691-704.

Preston, S.H., Wang, H., 2007. Intrinsic Growth Rates and Net Reproduction Rates in the Presence of Migration. Population and Development Review 33, 357-666.

Ratha, D., Shaw, W., 2007. South-South Migration and Remittances. World Bank Publications. Raymer, J., Abel, G., Smith, P.W., 2007. Combining census and registration data to estimate detailed elderly migration flows in England and Wales. Journal of the Royal Statistical Society: Series A (Statistics in Society) 170, 891-908.

Raymer, J., Abel, G.J., Rogers, A., forthcoming. Does specification matter? Experiments with simple multiregional probabilistic population projections. Environment and Planning A forthcoming. Raymer, J., Beer, J. de, Erf, R. van der, 2011. Putting the Pieces of the Puzzle Together: Age and Sex-Specific Estimates of Migration amongst Countries in the EU/EFTA, 2002-2007. European Journal of Population 27, 185-215.

Raymer, J., Forster, J.J., Smith, P.W.F., Bijak, J., Wiśniowski, A., 2012. Integrated Modelling of European Migration: Background, Specification and Results. NORFACE Migration Discussion Paper. Rees, P., 1980. Multistate demographic accounts: measurement and estimation procedures. Environment and Planning A 12, 499-531.

Reyes, B.I., 2004. Changes in Trip Duration for Mexican Immigrants to the United States. Population Research and Policy Review 23, 235-257.

Rivera-Batiz, F.L., Santiago, C.E., 1996. Island Paradox: Puerto Rico in the 1990s. Russell Sage Foundation.

Rogers, A., 1990. Requiem for the Net Migrant. Geographical Analysis 22, $283-300$.

Rogers, A., 1995. Multiregional Demography: Principles, Methods and Extensions. John Wiley, Chichester.

Rogers, A., Castro, L.J., 1981. Model migration schedules. IIASA Research Report 81, 1-160.

Rogers, A., Jones, B., Partida, V., Muhidin, S., 2007. Inferring migration flows from the migration propensities of infants: Mexico and Indonesia. Ann Reg Sci 41, 443-465.

Rogers, A., Little, J., 1994. Parameterizing age patterns of demographic rates with the multiexponential model schedule*. Mathematical Population Studies 4, 175-195.

Rogers, A., Little, J., Raymer, J., 2010. The indirect estimation of migration: Methods for dealing with irregular, inadequate, and missing data. Springer.

Rumbaut, R.G., 1989. The Structure of Refuge: Southeast Asian Refugees in the United States, 1975-1985 (SSRN Scholarly Paper No. ID 1886685). Social Science Research Network, Rochester, NY. Rumbaut, R.G., 1994. Origins and destinies: Immigration to the United States since World War II. Sociol Forum 9, 583-621.

Sadiq, K., 2009. When Being Native is Not Enough: Citizens as Foreigners in Malaysia. Asian Perspective 33, 5-32.

Sassen, S., 1998. The Migration of Capital and Labour. Cambridge University Press, Cambridge. Skeldon, R., 2006. Interlinkages between internal and international migration and development in the Asian region. Population, Space and Place 12, 15-30.

Spener, D., 2009. Clandestine Crossings: Migrants and Coyotes on the Texas-Mexico Border. Cornell 
University Press.

Spilimbergo, A., Hanson, G.H., 1999. Illegal Immigration, Border Enforcement, and Relative Wages:

Evidence from Apprehensions at the U.S.-Mexico Border. American Economic Review 89, 1337-1357.

Stark, O., Bloom, D.E., 1985. The New Economics of Labor Migration. The American Economic

Review 75, 173-178.

Stark, O., Taylor, J.E., 1991. Migration Incentives, Migration Types: The Role of Relative Deprivation.

The Economic Journal 101, 1163.

Statistics Canada, 2006. Immigration and Citizenship, 2006 Census. Ottawa, Canada.

Stojanov, R., 2008. Environmental Factors of Migration, in: Development, Environment and Migration.

Analysis of Linkages and Consequences. Palacky University, Olomouc.

Telles, E.E., Sue, C.A., 2009. Race Mixture: Boundary Crossing in Comparative Perspective. Annual

Review of Sociology 35, 129-146.

Thielemann, E., 2005. Does Policy Matter? On Governments' Attempts to Control Unwanted Migration (SSRN Scholarly Paper No. ID 495631). Social Science Research Network, Rochester, NY.

Todaro, M.P., Maruszko, L., 1987. Illegal Migration and US Immigration Reform: A Conceptual Framework. Population and Development Review 13, 101-114.

Tsuda, T., 2003. Strangers in the Ethnic Homeland: Japanese Brazilian Return Migration in Transnational Perspective. Columbia University Press.

UN, 2012. International Human Development Indicators.

UNHCR, 2012. Statistical Yearbook 2011: Ten Years of Statistics. New York.

United Nations, 2000. Millennium Development Goals Indicators [WWW Document]. URL

http://mdgs.un.org/unsd/mdg/Host.aspx?Content=Indicators/OfficialList.htm

UNPD, 2009. International Migrant Flows To and From Selected Countries: The 2008 Revision. United

Nations Population Division, New York.

UNPD, 2011. World population prospects: the 2010 revision. United Nations Population Division, New

York.

UNPD, 2012. Trends in International Migrant Stock: Migrants by Destination and Origin. United Nations Population Division, New York.

VanWey, L.K., 2005. Land Ownership as a Determinant of International and Internal Migration in Mexico and Internal Migration in Thailand1. International Migration Review 39, 141-172.

Willekens, F., 1999. Modeling approaches to the indirect estimation of migration flows: From entropy to EM. Mathematical Population Studies 7, 239-278.

Wilson, T., 2010. Model migration schedules incorporating student migration peaks. Demographic Research 23, 191-222.

Wilson, T., 2011. A Review of Sub-Regional Population Projection Methods. The University of Queensland Working Paper.

Wilson, T., Bell, M., 2004. Comparative empirical evaluations of internal migration models in subnational population projections. Journal of Population Research 21, 127-160.

Wu, Z., Li, N., 2003. Immigration and the dependency ratio of a host population. Mathematical Population Studies 10, 21-39. 
Zlotnik, H., 1998. International Migration 1965-96: An Overview. Population and Development Review 24, 429-468.

Zlotnik, H., 1999. Trends of International Migration since 1965: What Existing Data Reveal. International Migration 37, 21-61.

Zlotnik, H., 2004. Population growth and international migration. International migration: Prospects and policies in a global market 13-34.

Zlotnik, H., 2005. International migration trends since 1980. International Migration and the Millennium Development Goals 13.

Zolberg, A.R., Suhrke, A., Aguayo, S., 1989. Escape from violence: Conflict and the refugee crisis in the developing world. Oxford University Press, USA. 


\section{Appendix: Full List of Arguments}

\section{(1) ECONOMIC DEVELOPMENT}

1.1 Remittances will become more important for the economic development of migrant-sending countries.

1.2 The EU "Blue Card" skilled immigration scheme will attract more highly-qualified migrant workers from non-EU countries on a temporary basis.

1.3 Per capita income differentials between Asian countries will further widen.

1.4 Temporary labor migration will increasingly compensate for skills shortages in developed countries and thus replace permanent migration.

1.5 Foreign direct investment in developing countries as a stimulus to economic growth will rectify the imbalance between supply and demand in the labor market in those countries.

1.6 There will be a global convergence in returns to human capital.

1.7 Major economic recessions/stagnation in industrialized countries will lead to less demand for migrants.

1.8 Global wage levels will converge in the long run.

\section{(2) CLIMATE CHANGE}

2.1 International migration from low-lying coastal areas and small islands in the developing world will increasingly be driven by the negative impacts of climate change.

2.2 Populations in the Mediterranean region that are negatively affected by climate change will be successful in developing adaptive strategies.

2.3 Governments of North Africa and the Middle East will find peaceful resolutions to intensifying water and land-use conflicts.

2.4 Relatively better educated populations will have a higher adaptive capacity to the negative impacts of climate change.

2.5 Climate change will lead to conflict in poor countries and mass migration of asylum seekers to countries in the North.

2.6 Climate change will lead to new directions of migration such as from India or the Middle East to Siberia.

\section{(3) DEMOGRAPHIC FACTORS}

3.1 Shifts in cohort size, especially related to the baby boom and bust, will play an important role in shaping international migration levels.

3.2 Strategies for ensuring the provision of adequate health and care services to the growing elderly populations in OECD countries will increasingly draw on immigrant workers. 
3.3 The propensity to move abroad among 15 to 29 year olds will be particularly high in countries with a large "youth bulge".

3.4 Aging societies will be less open to immigration from different cultures.

3.5 More highly educated people will be more likely to migrate.

\section{(4) COST OF MIGRATION}

4.1 Populations in developing countries will develop a more realistic perception of life in developed countries through information technology.

4.2 Air travel and international freight will become less expensive, thus reducing the financial costs of migration.

4.3 Communication technologies will be a viable alternative to face-to-face communication with friends and relatives left behind, thus reducing the psychic cost of migration.

4.4 Increasing multiculturalism in developed countries will reduce the linguistic and cultural barriers to migration.

4.5 International migration will mostly follow established paths and existing migrant networks. 4.6 Migrant networks are not as relevant for the migration of more educated people.

\section{(5) MIGRATION REGIMES AND POLICY}

5.1 Among countries of the European Union, freedom of movement will make it impossible for governments to influence migration.

5.2 Political instability and oppression in African and Middle Eastern countries will result in more people seeking political asylum in democratic countries.

5.3 Developed countries will be largely unsuccessful in reducing undocumented migration through the tightening of immigration policies and the strengthening of border controls. 5.4 Family reunification policies in Western societies will support the right of a family to live together in the destination country.

5.5 Rich countries will tighten their student visa systems. 


\section{VIENNA INSTITUTE OF DEMOGRAPHY}

\section{Working Papers}

Caselli, Graziella, Sven Drefahl, Marc Luy and Christian Wegner-Siegmundt, Future Mortality in Low-Mortality Countries, VID Working Paper 06/2013

Basten, Stuart, Tomáš Sobotka and Kryštof Zeman, Future Fertility in Low Fertility Countries, VID Working Paper 05/2013.

Sharygin, Ethan, The Carbon Cost of an Educated Future: A Consumer Lifestyle Approach, VID Working Paper 04/2013.

Winkler-Dworak, Maria and Heiner Kaden, The Longevity of Academicians: Evidence from the Saxonian Academy of Sciences and Humanities in Leipzig, VID Working Paper 03/2013.

Feichtinger, Gustav, Alexia Prskawetz, Andrea Seidl, Christa Simon and Stefan Wrzaczek, Do Egalitarian Societies Boost Fertility?, VID Working Paper 02/2013.

Muttarak, Raya, Is it (dis)Advantageous to Have Mixed Parentage? Exploring Education \& Work Characteristics of Children of Interethnic Unions in Britain?, VID Working Paper 01/2013.

Testa, Maria Rita and Stuart Basten, Have Lifetime Fertility Intentions Declined During the "Great Recession"?, VID Working Paper 09/2012.

Buber, Isabella, Ralina Panova, and Jürgen Dorbritz, Fertility Intentions of Highly Educated Men and Women and the Rush Hour of Life, VID Working Paper 08/2012.

Testa, Maria Rita, Laura Cavalli, and Alessandro Rosina, The Decision of Whether to Have a Child: Does Couple Disagreement Matter?, VID Working Paper 07/2012.

Kuhn, Michael and Klaus Prettner, Growth and Welfare Effects of Health Care in Knowledge Based Economies, VID Working Paper 06/2012.

Sander, Nikola and Martin Bell, Age, Period and Cohort Effects on Migration of the Baby Boomers in Australia, VID Working Paper 05/2012.

Grafeneder-Weissteiner, Theresa, Ingrid Kubin, Klaus Prettner, Alexia Prskawetz, and Stefan Wrzaczek, Coping with Inefficiencies in a New Economic Geography Model, VID Working Paper 04/2012.

Goujon, Anne, Éric Caron Malenfant, and Vegard Skirbekk, Towards a Catholic North America? Projections of Religion in Canada and the US beyond the Mid-21 st Century, VID Working Paper 03/2012.

The Vienna Institute of Demography Working Paper Series receives only limited review. Views or opinions expressed herein are entirely those of the authors. 